Cómo citar este trabajo: Gutiérrez Hernández, O., \& García, L. V. (2019). La dimensión geográfica de las invasiones biológicas en el Antropoceno: el caso de Xylella fastidiosa. Boletín de la Asociación de Geógrafos Españoles, 80, 2771, 1-32. http://dx.doi.org/10.21138/bage.2771

\title{
La dimensión geográfica de las invasiones biológicas en el Antropoceno: el caso de Xylella fastidiosa
}

The geographical dimension of biological invasions in the Anthropocene: the case of Xylella fastidiosa

\section{Oliver Gutiérrez Hernández}

\author{
olivergh@uma.es \\ Departamento de Geografía \\ Universidad de Málaga (España) \\ Luis V. García \\ ventura@cica.es \\ Instituto de Recursos Naturales y Agrobiología \\ Consejo Superior de Investigaciones Cientificas (España)
}

\begin{abstract}
Resumen
Xylella fastidiosa es una bacteria potencialmente dañina para un gran número de cultivos leñosos y especies arbóreas, y está considerada una de las bacterias fitopatógenas más peligrosas del mundo. En este artículo, combinamos modelos de nicho ecológico para estimar la distribución potencial global de $X$. fastidiosa y, complementariamente, técnicas de evaluación multicriterio para estimar regionalmente la exposición de la península Ibérica e islas Baleares a la entrada y difusión del patógeno. A nivel global, nuestros modelos estimaron una distribución potencial de $X$. fastidiosa con un amplio radio potencial de expansión en climas templados (Grupo C, según la clasificación climática de Köppen). A nivel regional, nuestros resultados revelaron que la península Ibérica se halla muy expuesta a la entrada y propagación de este organismo invasor, cuya presencia es ya


generalizada en las islas Baleares. En el Antropoceno, la Geografía desempeña un papel crucial en el manejo de los riesgos biológicos. El éxito en la gestión de los mismos depende, en gran medida, de nuestra capacidad para predecir los rangos geográficos potenciales de los organismos invasores e identificar los factores que promueven su propagación.

Palabras clave: Biogeografía; riesgos biológicos; modelos de nicho ecológico; evaluación multicriterio; Análisis Geográfico Regional.

\begin{abstract}
Xylella fastidiosa is a potentially harmful organism for a large number of woody crops and tree species, being considered one of the most dangerous phytopathogenic bacteria worldwide. In this article, we used Ecological Niche Models (ENM) to predict the global potential distribution of $X$. fastidiosa, and at the regional level, Multi Criteria Evaluation (MCE) methods to predict the risk of exposure to this pathogen in the Iberian Peninsula and Balearic Islands. At the global level, our models predicted a wide potential distribution of $X$. fastidiosa with a wide potential radius of expansion temperate climates (Group C, Köppen climate classification). At regional level, our results revealed the Iberian Peninsula is very exposed to the entry and spread of this invasive organism, whose presence is already widespread in the Balearic Islands. In the Anthropocene epoch, Geography plays a crucial role in a management of biological risks because of a successful management depends heavily on our ability to predict potential geographical ranges of invasive organisms and to identify main factors that promote their spread.
\end{abstract}

Key words: Biogeography; biological risks; ecological niche models; multicriteria decision analysis; Regional Geographic Analysis.

\title{
1 Introducción
}

\subsection{Las invasiones biológicas y la emergencia de Xylella fastidiosa}

El Antropoceno es considerado una época funcional y estratigráficamente diferente del Hocoleno (Waters et al., 2016). En esta nueva naturaleza ligada a los efectos del ser humano, una de las manifestaciones más orgánicas es la incesante recomposición del mapa biogeográfico de la Tierra, como consecuencia de la dispersión de especies exóticas inducida por la actividad humana (Capinha et al., 2015; Miraldo et al., 2016; Murray et al., 2015; Waters et al., 2016).

Entre las especies exóticas dispersadas por el hombre se cuentan numerosas especies invasoras con un gran potencial patogénico (Colautti et al., 2014; Murray, Olivero et al., 2018). Hasta el momento, los esfuerzos realizados para mitigar las invasiones biológicas no han sido del todo efectivos y algunos autores sostienen que se trata de un problema de difícil solución (Seebens et 
al., 2017). Por ejemplo, se estima que en los Estados Unidos de América existen actualmente más de 50000 especies exóticas; dentro de las cuales, las especies invasoras provocan anualmente pérdidas económicas millonarias (Pimentel et al., 2005).

Xylella fastidiosa es una de las bacterias fitopatógenas más peligrosas del mundo (Mansfield et al., 2012; Rapicavoli, et al., 2018; Sicard et al., 2018; Wells et al., 1987). Se trata de una bacteria confinada en el xilema de las plantas cuya patogenicidad la convierte en un organismo potencialmente dañino para un gran número de cultivos leñosos (Figura 1). De acuerdo con los últimos datos de la Autoridad Europea de Seguridad Alimentaria (European Food Safety Authority, EFSA) (actualizado a 13/01/2019), se ha encontrado X. fastidiosa en 563 especies hospedantes. Entre ellos destacan el olivo, el almendro, la vid o los cítricos (Almeida \& Purcell, 2003; Araújo et al., 2002; Bucci, 2018; Hopkins, 1989; Janse \& Obradovic, 2010; Loconsole et al., 2014). La bacteria se transmite por numerosos insectos vectores (cicadélidos y cercópidos), hemípteros chupadores que se alimentan a partir del xilema (Almeida, Coletta-Filho \& Lopes, 2014; Morente et al., 2018). Se multiplica en el interior del xilema llegando a obstruir el flujo de savia en la planta (Almeida, Coletta-Filho \& Lopes, 2014; Lima et al., 1998; Redak et al., 2004). Los síntomas varían según la especie y el estadio de la infección: clorosis, marchitez, necrosis foliar, hojas y ramas secas y decaimiento generalizado (Landa, et al., 2017). Por tanto, estamos ante un organismo que vive entre dos mundos: el huésped y el vector (Chatterjee, et al., 2008).

Originaria del continente americano (Nunney et al., 2014), Xylella fastidiosa se ha detectado, además, en Europa y Asia. El potencial de dispersión de X. fastidiosa no sólo radica en la capacidad dispersiva de los insectos vectores, que realmente sólo son operan a corta distancia (Banks et al., 2015), sino, sobre todo, en el comercio y transporte del material vegetal infectado (Seebens et al., 2015; Tingley, et al., 2018). Hace 20 años su dispersión ya se consideraba una amenaza global (Purcell, 1997); ahora la preocupación se ha trasladado continente europeo (Jeger et al., 2018; Strona et al., 2017).

En 2013, se informó del primer registro de presencia de Xylella fastidiosa en condiciones de campo abierto (olivar) en un país miembro de la Unión Europea, en concreto, en la región de Apulia (Saponari et al., 2018). Desde entonces se han producido daños gravísimos en los olivares de dicha región (Carlucci, et al., 2013; Mang, et al., 2016), lo cual ha llevado a las autoridades regionales a declarar el estado de emergencia fitosanitaria (http://www.emergenzaxylella.it). En noviembre 2016, se reporta el primer registro de presencia en las Islas Baleares (Gutiérrez et al., 2018) y en 2017 se detectan los primeros brotes de $X$. fastidiosa en sureste de la península Ibérica (Giampetruzzi et al., 2018). Ya en 2018, se detectó la presencia del patógeno en otros enclaves puntuales del centro de la península lbérica y en región italiana de la Toscana, al tiempo que prosigue su avance en el sureste (Alicante). En España, la situación mantiene muy preocupado 
al sector agrícola y a las administraciones competentes. Los medios de comunicación se refieren continuamente al problema y a los riesgos que comporta. El último informe de la Autoridad Europea para la Seguridad de los Alimentos (EFSA, European Food Safety Authority) concluye que, aunque las zonas donde actualmente se encuentra $X$. fastidiosa están claramente demarcadas, es más que probable que asistamos a una propagación del organismo en el continente, pues no son pocas las incertidumbres en torno a difusión del patógeno en nuevos ecosistemas, donde incluso puede permanecer silente largos periodos de tiempo sin ser detectado (leger et al., 2018).

Figura 1. 1) Olivos afectados por Xylella fastidiosa; 2) Necrosis y marchitamiento en hojas de vid por el patógeno; 3) Philaenus spumarius, uno de los vectores del patógeno; 4) La bacteria $X$. fastidiosa a vista de microscopio, en una sección transversal del vaso del xilema
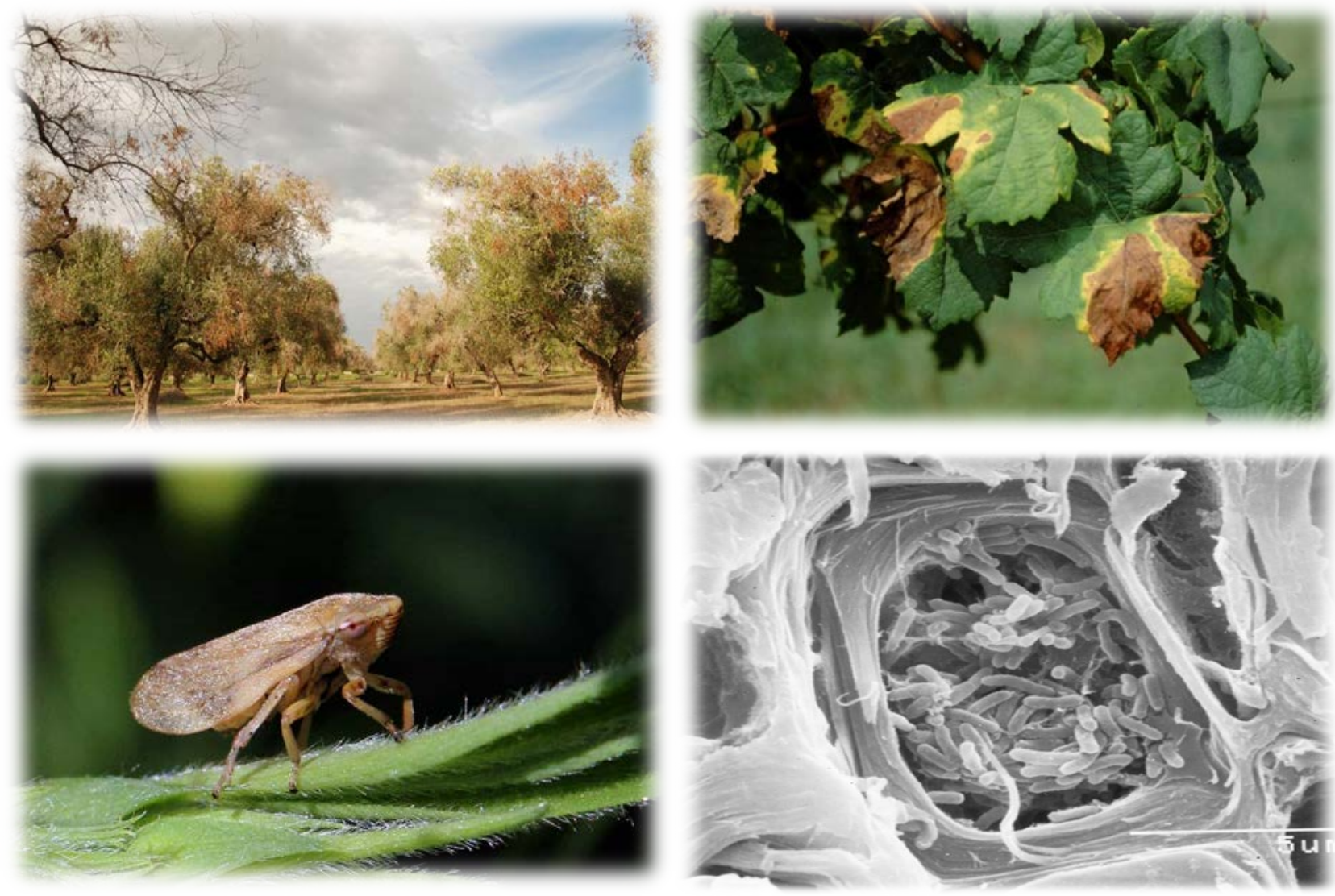

Fuente: fotos 1 y 2, Mediterranean Plant Protection Organization (EPPO, 2018); foto 3, Charles J. Sharp (2018); y foto 4 (Lima et al., 1998)

\subsection{La Geografía ante las invasiones biológicas}

El estudio de los riesgos naturales siempre ha constituido una de las ramas más activas, fecundas y reconocidas de la Geografía aplicada (Ayala Carcedo \& Olcina Cantos, 2002), especialmente en el análisis de las inundaciones, los fenómenos geomorfológicos y los incendios forestales (Montz \& Tobin, 2011). 
Sin embargo, el estudio geográfico de los riesgos biológicos, y en concreto, las consecuencias de las invasiones biológicas, todavía asoma en lontananza como unos de los campos menos explorados por la comunidad de geógrafos.

Las evidencias ponen de manifiesto que las invasiones biológicas constituyen un conjunto de fenómenos multifactoriales que trascienden las fronteras de la biología y la ecología y se imbrican en el complejo panorama de la globalización, difuso ecotono global en el que la geografía se halla en el meollo de la problemática (Packer et al., 2017). Algunos autores sostienen que la Biogeografía debería adoptar un rol fundamental en el estudio de la distribución de los riesgos biológicos y la incidencia de los patógenos en los sistemas socioecológicos, en un nuevo campo de conocimiento que se ha denominado "Patogeografía" (Murray et al., 2015, 2018).

Este trabajo pretende reivindicar la relevancia de la geografía y el análisis de datos geoespaciales en el marco del estudio de la dinámica de las especies exóticas invasoras que protagonizan los principales riesgos biológicos del momento.

La perspectiva espacial de la Geografía (en mayúscula) no sólo permite incorporar una aproximación vinculada con la ecología de los organismos biológicos para estimar la distribución potencial de los mismos sino, que, además, implementa la propia geografía (en minúscula) de los drivers (factores geográficos) o motores de la diáspora de los organismos invasores, como vectores geográficos que pueden explicar la propagación de estos seres vivos por la influencia de las actividades humanas (Rodríguez-Labajos, et al., 2009). Si la ecología de las especies informa hasta donde puede llegar un organismo, es la geografía de las relaciones hombre-medio aquella que nos indica por dónde sería más factible que los organismos invasores colonizaran nuevos espacios siguiendo rutas y cruzando barreras biogeográficas (Essl et al., 2015).

Dado que la propagación de Xylella fastidiosa en la península Ibérica podría suponer auténtico un desastre para los agrosistemas mediterráneos y la economía de los espacios rurales (Bucci, 2018), se requiere una doble aproximación que estudie tanto el área de distribución potencial del patógeno (Elith, 2017), como la influencia de los drivers que pudieran facilitar su llegada y propagación (Rodríguez-Labajos et al., 2009). Este enfoque trasciende la aproximación basada en la probabilidad de presencia, dado que es muy difícil estimar esta probabilidad cuando estamos ante un organismo en proceso de expansión fuera de su rango nativo (Václavík \& Meentemeyer, 2009), por lo que es también pertinente incorporar una aproximación complementaria basada en la teoría de conjuntos borrosos (Eastman, 1999; Jiang \& Eastman, 2000). 


\subsection{Objetivos}

El presente trabajo tiene dos objetivos fundamentales:

1. A escala mundial, estimar la distribución potencial global de Xyella fastidiosa a través de un ensamblaje de modelos de nicho ecológico basado en dałos bioclimáticos.

2. A escala regional, estimar la exposición de la península lbérica e islas Baleares a la llegada y / o propagación del Xyella fastidiosa, combinando los resultados del modelo de nicho ecológico con un conjunto drivers que pueden facilitar la dispersión del patógeno, y empleando para ello técnicas de evaluación multicriterio basadas en la teoría de conjuntos borrosos.

\section{Material y métodos}

\section{1 Áreas de estudio}

Globalmente (A1, Figura 2), para el estudio de la distribución potencial global de Xylella fastidiosa basado en el ensamblaje de modelos de nicho ecológico, el área de estudio abarcó toda la superficie de la Tierra: tierras emergidas. A nivel regional (A2, Figura 2), para la estimación del riesgo de exposición al patógeno, consideramos la península lbérica e Islas Baleares.

Figura 2. Área de estudio: A1) área de calibración global; A2) área de proyección regional
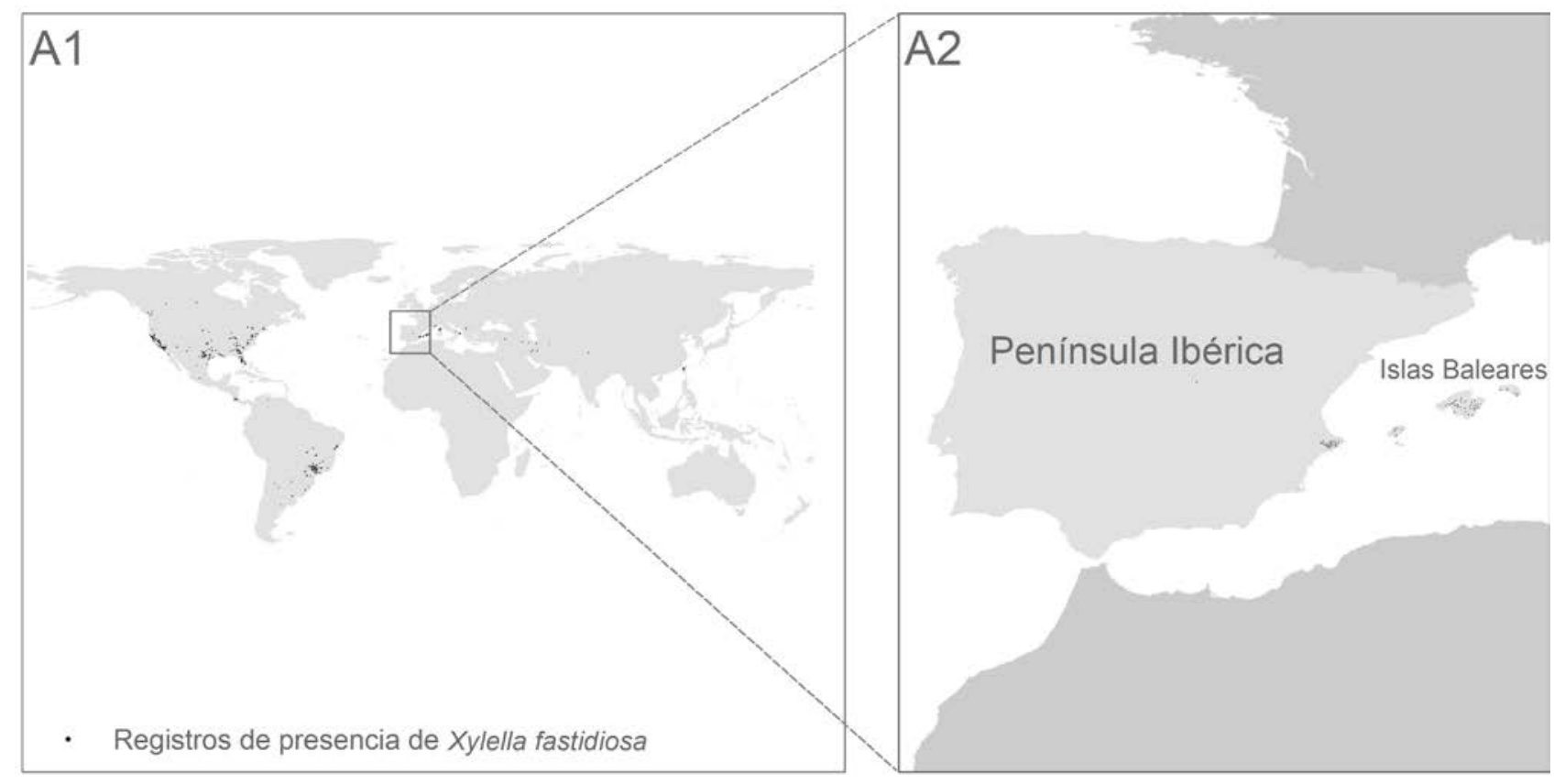

Fuente: elaboración propia a partir de los registros de presencia

de Xylella fastidiosa (EFSA, 2018) 


\subsection{Procesado de variables bioclimáticas}

En el marco global, analizamos la relación entre los registros de presencia de la bacteria y los factores ambientales y desarrollamos modelos de distribución potencial de Xylella fastidiosa (Guisan, et al., 2017; Gutiérrez Hernández, et al., 2018; Peterson et al., 2011). Para ello, utilizamos diecinueve variables bioclimáticas procedentes del repositorio Worldclim 2 (Fick \& Hijmans, 2017) y empleamos la clasificación de Köppen para facilitar la lectura de los factores bioclimáticos (Kottek et al., 2006). La resolución de los datos ambientales fue de 10 minutos (18,6 $\times 18,6 \mathrm{Km}=344 \mathrm{~km}^{2}$ en el ecuador) acorde con el sistema de coordenadas geográficas WGS84 (Tabla 1).

Tabla 1. Conjunto de variables bioclimáticas empleadas inicialmente

\begin{tabular}{|c|c|}
\hline CÓDIGO & VARIABLE \\
\hline Bio1 & Temperatura media anual \\
\hline Bio2 & Amplitud media diurna \\
\hline Bio3 & Isotermicidad (bio2/bio7) (* 100) \\
\hline Bio4 & Temperatura estacional (desviación estándar * 100) \\
\hline Bio5 & Temperatura máxima del mes más cálido \\
\hline Bio6 & Temperatura mínima del mes más frío \\
\hline Bio7 & Amplitud térmica anual (bio5-bio6) \\
\hline Bio8 & Temperatura media del trimestre más húmedo \\
\hline Bio9 & Temperatura media del trimestre más seco \\
\hline Bio10 & Temperatura media del trimestre más cálido \\
\hline Bio11 & Temperatura media del trimestre más frío \\
\hline Bio12 & Precipitación anual \\
\hline Bio13 & Precipitación del mes más lluvioso \\
\hline Bio14 & Precipitación del mes más seco \\
\hline Bio15 & Precipitación estacional (coeficiente de variación) \\
\hline Bio16 & Precipitación del trimestre más húmedo \\
\hline
\end{tabular}


Tabla 1. Continuación

\begin{tabular}{|c|c|}
\hline CÓDIGO & VARIABLE \\
\hline Bio17 & Precipitación del trimestre más seco \\
\hline Bio18 & Precipitación del trimestre más cálido \\
\hline Bio19 & Precipitación del trimestre más frío \\
\hline
\end{tabular}

Fuente: elaboración propia a partir de Wordlclim 2 (Fick \& Hijmans, 2017)

Como el uso de todas las variables bioclimáticas en los modelos estadísticos comportaría problemas de multicolinealidad debido que buena parte de las variables derivadas de temperatura y precipitación están correlacionadas entre sí, realizamos un Análisis de Componentes Principales de las variables bioclimáticas proyectadas en cada localización de los registros de presencia de Xylella fastidiosa (De Marco \& Nóbrega, 2018; Dormann et al., 2013). Este análisis estadístico se realizó en entorno de análisis de datos y producción de gráficos R (R Core Team, 2017).

El Análisis de Componentes Principales (ACP ó PCA, por sus siglas en lengua inglesa) se basa en la transformación de un conjunto de variables originales, en este caso los datos bioclimáticos, en otro conjunto de variables -o componentes Principales- obtenidos como combinación lineal de aquellas (Eastman, 2015). Las nuevas variables conservan toda la información de las variables primitivas, pero la mayoría de los componentes principales tienen una variabilidad tan pequeña que pueden ser ignorados, de forma que unos pocos componentes son suficientes para representar y explicar razonablemente el conjunto de objetos de la muestra sin pérdida importante de información (Guisande González et al., 2013). Así, el primer componente principal es la combinación lineal de las variables originales que tiene máxima varianza; el segundo componente es la combinación lineal de las variables originales con máxima varianza con la condición añadida de que sea independiente del primero (ortogonal), y así sucesivamente hasta obtener todos los componentes principales. Cada componente principal explica la máxima variabilidad residual posible, es decir, la que no han explicado los componentes anteriores. Por tanto, cada componente es independiente entre sí y contiene información distinta.

Finalmente, la principal ventaja del Análisis de Componentes Principales es precisamente la reducción de la complejidad de los datos, al pasar de muchas variables a unas pocas. Frente a esta ventaja, el inconveniente de las nuevas variables está en una reducida pérdida de información y en el hecho de que las variables originales tienen un significado real del que carecen en general los componentes, que son mezcla o combinación de variables. En nuestro caso, dada la finalidad predictiva del modelo de nicho ecológico, seleccionamos los primeras cinco componentes principales de acuerdo con el criterio de la varianza explicada acumulada (Jackson, 1993). 


\subsection{Definición de los drivers en el marco regional}

En el marco regional, proyectamos la distribución potencial del patógeno calibrada a nivel mundial sobre la península Ibérica e Islas Baleares, y establecimos una resolución de 30 segundos $(0,93 \times$ $0,93 \mathrm{~km}=0,86 \mathrm{~km}^{2}$ en el ecuador), de acuerdo con el sistema de coordenadas WGC84, para capturar una mayor variabilidad que en las predicciones realizadas con los modelos globales. En este estadio definido por una mayor resolución espacial, superpusimos los drivers para, combinados con el modelo de distribución potencial, estimar la exposición de la península Ibérica e Islas Baleares a la llegada y / o propagación de Xylella fastidiosa.

Denominamos drivers a los factores geográficos que se considera que favorecen la entrada y / o propagación de las invasiones biológicas. Para respaldar los criterios empleados, realizamos a una revisión de la literatura científica al respecto (Anderson et al., 2015; Benedetti \& Morelli, 2017; Bertelsmeier et al., 2017; Grosholz, 2018; Meurisse et al., 2018). Entre los drivers consideramos gradientes de proximidad con respecto a los principales nodos y redes de transporte, espacios agrícolas donde se importa material biológico y zonas pobladas donde el flujo de personas es máximo. Aplicamos distintas funciones de pertenencia borrosa según la naturaleza de cada driver considerado. En conjunto, generamos siete drivers (Tabla 2).

\section{Tabla 2. Conjunto de drivers empleados}

\begin{tabular}{|c|c|c|}
\hline CÓDIGO & VARIABLE & FUNCIÓN DE PERTINENCIA BORROSA \\
\hline fuzzy_road & Proximidad a carreteras & Lineal \\
\hline fuzzy_crop & Proximidad a cultivos & Gaussiana \\
\hline fuzzy_pob & Densidad de población Nut3 & Alta difusa \\
\hline fuzzy_airport & Proximidad a aeropuertos & Alta difusa \\
\hline fuzzy_port & Proximidad a puertos & Alta difusa \\
\hline fuzzy_urban & Proximidad a zonas urbanas & Lineal \\
\hline fuzzy_ffcc & Proximidad a ferrocarriles & \\
\hline
\end{tabular}

Fuente: elaboración propia

Con la función lineal, la pertenencia aumenta linealmente con la proximidad. Esta función se aplicó a las redes de transporte y espacios cultivados. Aplicamos la función gaussiana para penalizar áreas hiperpobladas y zonas muy despobladas y sobrevalorar valores entorno al promedio, puesto que consideramos que son los espacios periurbanos y rurales medianamente poblados donde se introduce mayor material biológico, bien para explotaciones agrícolas o la jardinería urbana y 
residencial. Finalmente, con la función alta difusa, ponderamos positivamente una proximidad por encima de un umbral establecido cerca de los principales nodos de transporte.

\subsection{Diseño del muestreo}

En nuestro esquema metodológico, los registros de presencia componen la variable dependiente (y) que se relaciona con las variables independientes o predictoras $(x)$. Esta relación de $y=f(x)$ que permite determinar correspondencias es factible mediante métodos estadísticos. En principio, trabajamos con 1744 registros de presencia de Xylella fastidiosa distribuidos por todo el mundo (Delbianco et al., 2019), pero diseñamos una estrategia de muestreo para garantizar una mayor independencia estadística de los datos georreferenciados. En la Figura 3 (derecha), se aprecia el diseño de muestreo aplicado a todos los registros de presencia del patógeno.

Figura 3. Detalle de la cuadrícula de muestreo (levante de la península lbérica)
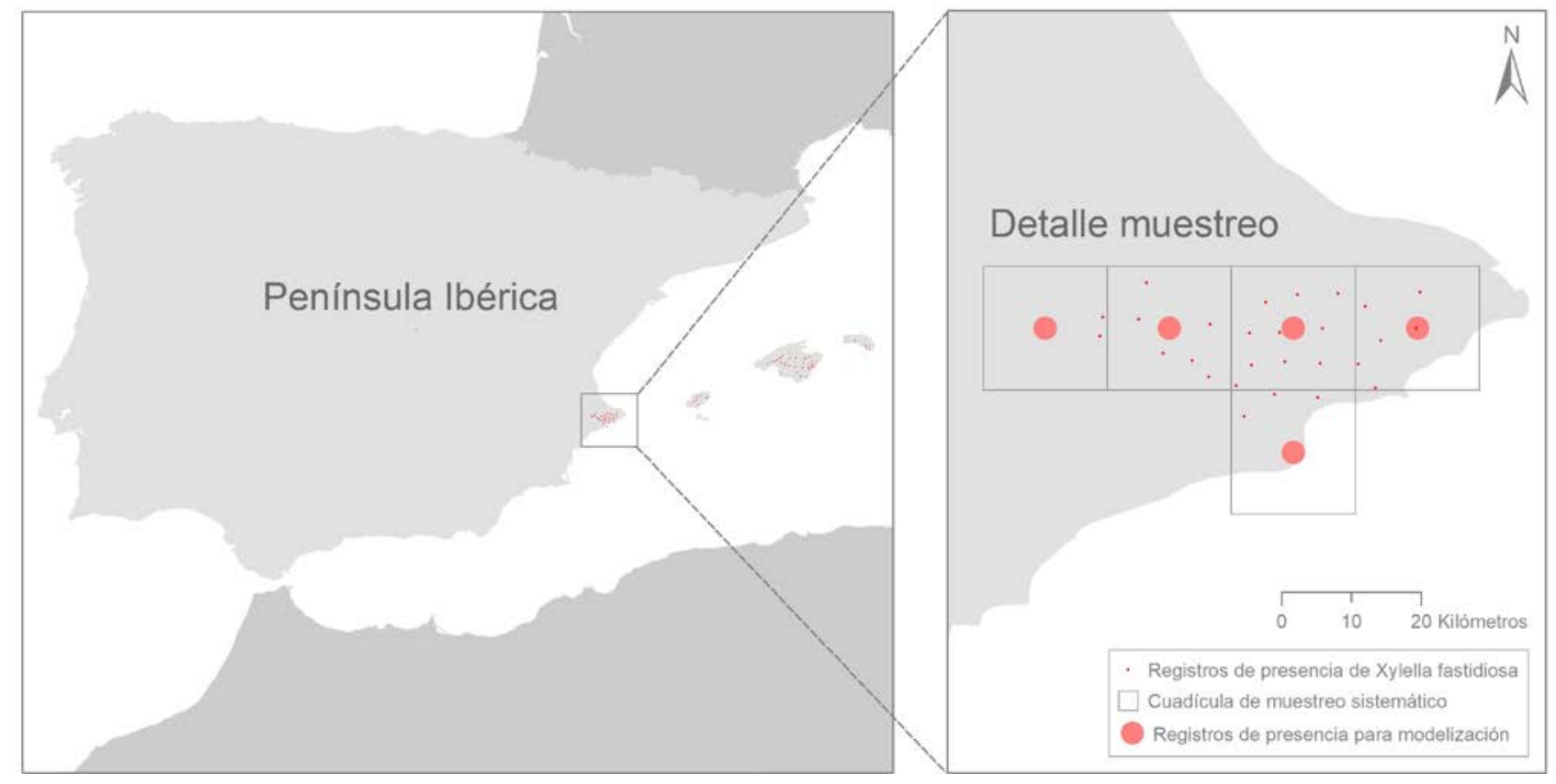

Fuente: elaboración propia a partir de los registros de presencia de Xylella fastidiosa (EFSA, 2018)

Así, redujimos el tamaño de la muestra con una primera selección aleatoria para así disminuir el efecto de la autocorrelación espacial de los registros de presencia. Debido a que, posteriormente, fijaríamos la resolución de los predictores (mapas raster) en una malla de 10 minutos (WGS84), establecimos un máximo de un punto (registro de presencia) dentro de cada píxel (o factor), para evitar los efectos negativos que sobre los procedimientos estadísticos tiene la pseudorreplicación entre variables independientes y variables dependientes (Guisan \& Zimmermann, 2000).

En teoría, los registros de ausencia son las localizaciones donde consideramos que la especie no está presente. Si un registro de presencia es un hecho basado en una o varias observaciones; un 
registro de ausencia tiene una naturaleza más compleja que puede expresar diferentes significados: una ausencia podría estar causada por cuestiones biogeográficas y/o requisitos ambientales, pero también por un deficiente esfuerzo de muestreo (Lobo et al., 2010). Dado el carácter invasor de Xylella fastidiosa, que se encuentra en plena diáspora, descartamos por principio el uso de registros de ausencia: no tenemos certeza sobre las ausencias (Václavík \& Meentemeyer, 2009). Pero en su lugar, empleamos datos de fondo (o background) para entrenar los modelos. El background se define como una nube de puntos aleatorios que caracterizan los ambientes del área de estudio. Bajo este paradigma, los modelos se calibran usando puntos aleatorios en toda el área de estudio sin una relación de exclusión -las ausencias- predefinida, porque un dato de fondo puede aparecer incluso sobre un registro de presencia. La clave está en que los métodos de inteligencia artificial que describiremos a continuación, adecuadamente calibrados y replicados en distintas iteraciones, tomarán como poco relevante esta excepcionalidad alejada del patrón general. Por tanto, resulta crítica la selección y calibración de algoritmos procedentes del campo de la minería de datos. Es el paso siguiente.

\subsection{Modelos predictivos y evaluación multicriterio}

Empleamos dos potentes algoritmos predictivos: Maxent (Máxima Entropía) y MARS (Multivariate Adaptative Regression Splines). Maxent es un algoritmo que maximiza la entropía bajo las restricciones de los factores en busca de la distribución más uniforme posible, y resulta especialmente útil cuando se dispone de pocos registros de presencia (Phillips et al., 2016; Phillips \& Dudi, 2008). Por su parte, MARS es un algoritmo que permite modelar directamente respuestas no lineales mediante un suavizado (smoothing) de las variables predictivas (Friedman, 1991). Es un método de regresión no lineal y no paramétrico, porque trabaja con valores suavizados de cada variable que en conjunto pueden adoptar una respuesta no lineal y es el propio modelo el que se ajusta empíricamente generando múltiples curvas (splines)

Desarrollamos 25 réplicas por cada algoritmo, Maxent y MARS, seleccionando los registros de presencia (y el background) aleatoriamente en cada iteración mediante el procedimiento de muestreo de Bootstrapping (Efron, 1981). En total, generamos 50 modelos independientes evaluados sistemáticamente. Por un lado, evaluamos el grado de ajuste de los modelos a partir de la matriz de confusión representando los resultados en la Curva ROC (acrónimo de Receiver Operating Characteristic) para obtener el Área Bajo la Curva o AUC (acrónimo de Area Under the Curve) (Fielding \& Bell, 1997). Por otro lado, dado que no empleamos registros de ausencia sensu stricto en la matriz de confusión, con el AUC no estaríamos determinando realmente una verdadera capacidad discriminante de los modelos (Lobo, et al., 2008). Complementariamente, estimamos una medida de calibración que relaciona la probabilidad de ocurrencia estimada por los modelos y la proporción ocurrencias observadas (Franklin, 2009). Tanto la calibración como la evaluación de 
modelos se realizó empleando la librería "sdm" (Naimi \& Araújo, 2016), del entorno de programación y análisis de datos $\mathrm{R}$.

Evaluado el modelo, proyectamos las predicciones espaciales a partir del ensamblaje de modelos de nicho ecológico (50 réplicas) y generamos un mapa de distribución potencial global de Xylella fastidiosa a 10 minutos de resolución espacial.

Finalmente, proyectamos la distribución potencial del organismo patógeno sobre la península Ibérica e Islas Baleares a mayor detalle (30 segundos de resolución espacial); y estimamos, además, el grado de exposición de este contexto regional con respecto a la entrada y/o propagación del patógeno, mediante una superposición difusa los drivers considerados. En el marco de la superposición difusa (fuzzy overlay), empleamos la función suma difusa, combinación lineal creciente que está basada en el número de criterios introducidos en el análisis, donde la evidencia combinada es más importante que cualquier evidencia simple.

\section{Resultados}

\subsection{Reducción de la dimensionalidad de los predictores}

En la Figura 4, representamos dos gráficos del ACP. En primer lugar, empleamos el círculo de correlación de las variables bioclimáticas con los dos primeros componentes principales, que, conjuntamente, explican el 61,35\% de la varianza de la variación total: el primer componente contribuye con el 39,45\% y el segundo con el 21,90\%. En general, la mayor parte de las variables se relacionaron positivamente con el primer eje, excepto bio2, bio4, bio5 y bio7. Tal es la intensidad de las correlaciones que encontramos posiciones casi idénticas en algunas variables: bio13 y bio 16; bio 14 y bio17. Las variables más importantes para el segundo eje se relacionaron con la precipitación con cargas positivas para la precipitación bio14 y bio17, y cargas negativas en bio15. En el gráfico de sedimentación (Scree plot), se ilustra cómo las primeras cinco componentes explican el $95 \%$ de la varianza explicada, por lo que el resto de componentes son prescindibles.

Por tanto, seleccionamos las primeras cinco componentes para emplearlas como predictores de los modelos de nicho ecológico. 
Figura 4. Análisis de componentes principales
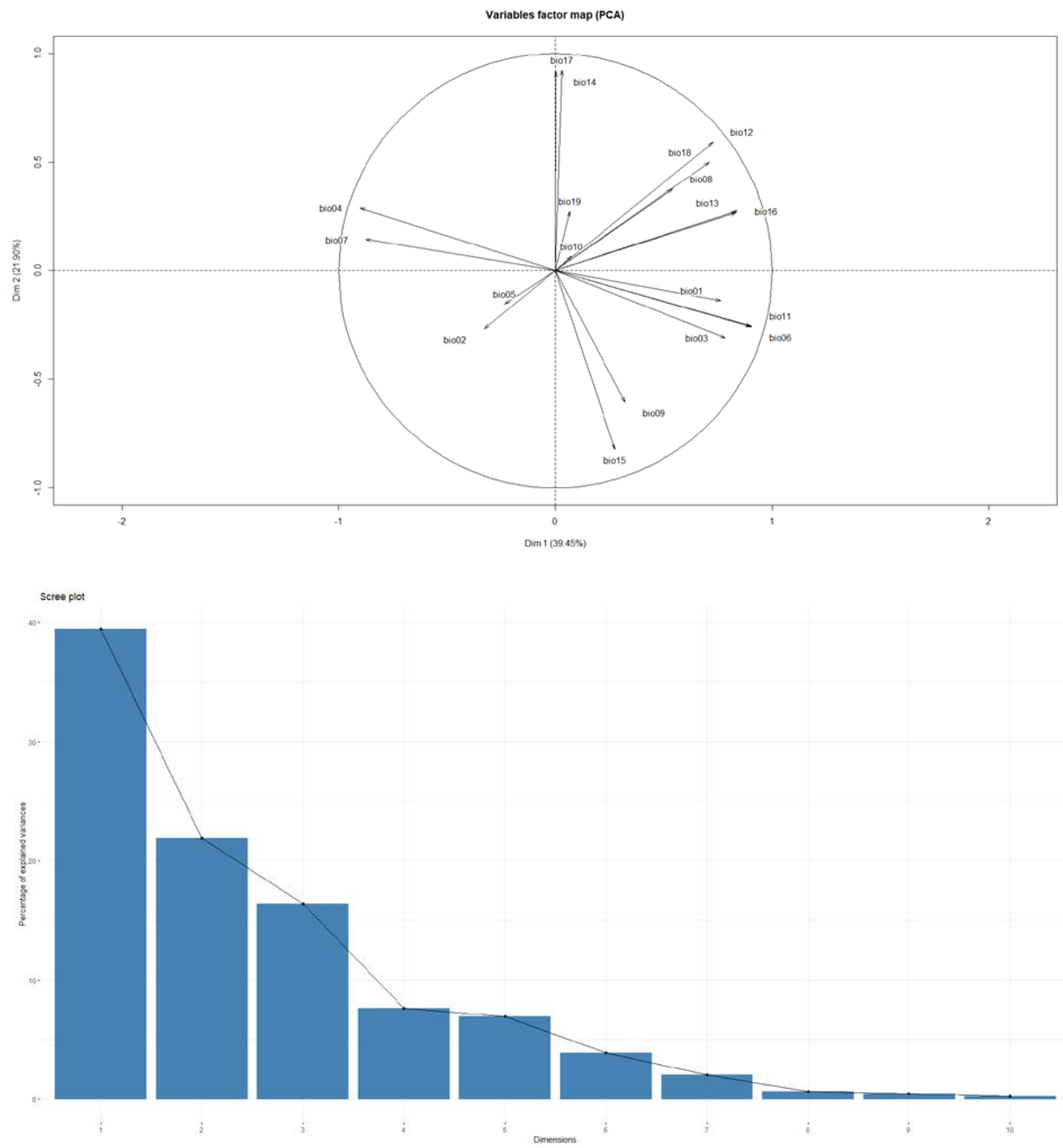

Fuente: elaboración propia

\subsection{Evaluación de los modelos de nicho ecológico}

El conjunto de modelos replicados con distintos datos ofreció un excelente grado de ajuste (considerado como AUC > 0,90), con valores de AUC por encima de 0,95. Si bien, hay que aclarar que el AUC calculado con datos de presencia / background informa sobre la capacidad del modelo para discernir entre un registro de presencia y un dato aleatorio, y no entre un registro de presencia y otro de ausencia. Por tanto, en este caso, hablamos de grado de ajuste más que de capacidad discriminante del modelo. Es importante valorar este punto porque nosotros no empleamos las ausencias ni para calibrar ni para evaluar los modelos dada la problemática de 
difícil solución que representan los registros de ausencia en el caso de las especies invasoras. Por tanto, la curva ROC y el AUC reportaron otra información muy útil: los modelos fueron ajustados, estables y mostraron un comportamiento similar en cada réplica, como se aprecia en las réplicas de cada curva (Figura 5), por lo que estamos en condiciones de ensamblar un conjunto de predicciones relativamente homogéneas y coherentes en su ajuste.

\section{Figura 5. Curva ROC y AUC}
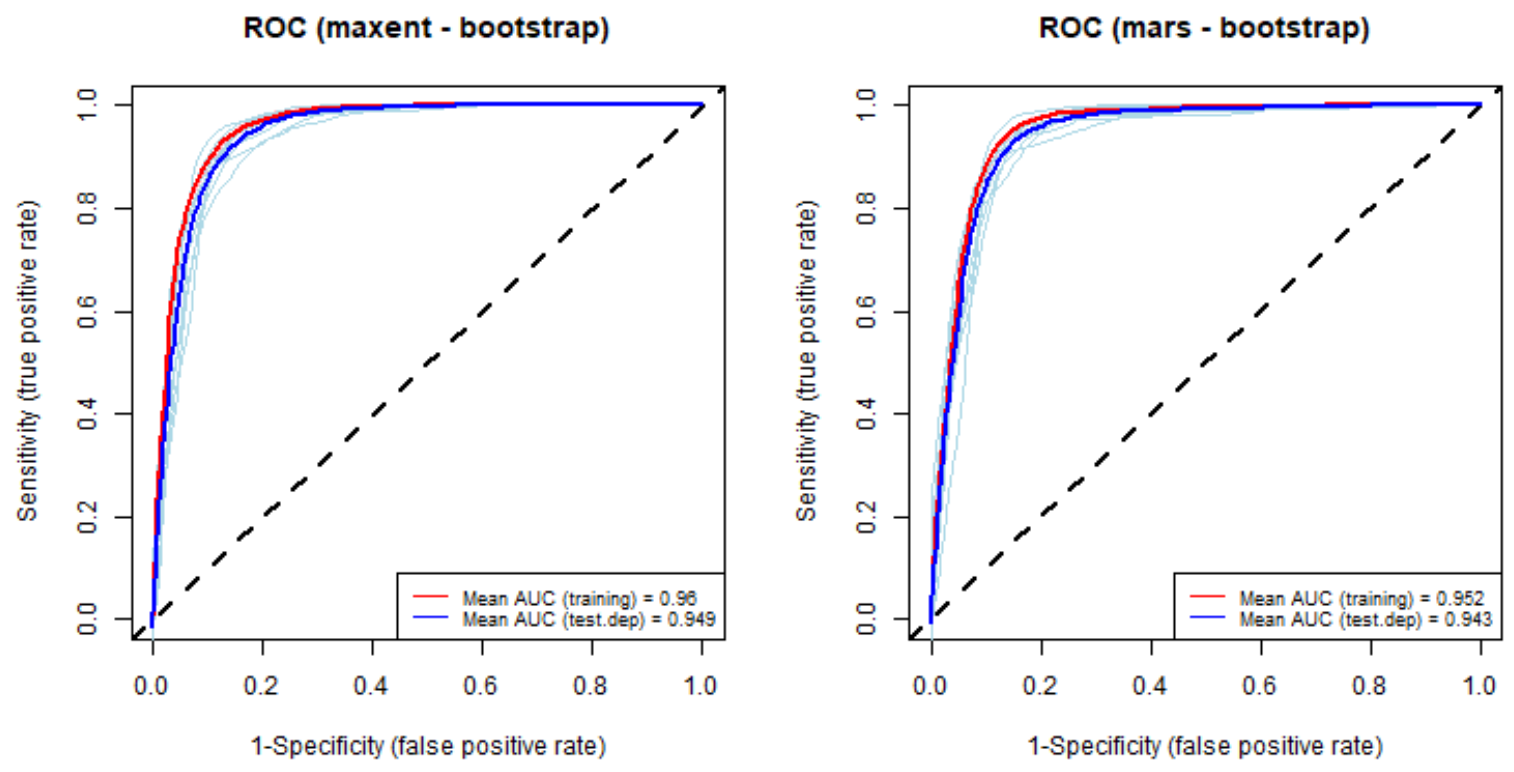

Fuente: elaboración propia

Figura 6. Gráfico de calibración

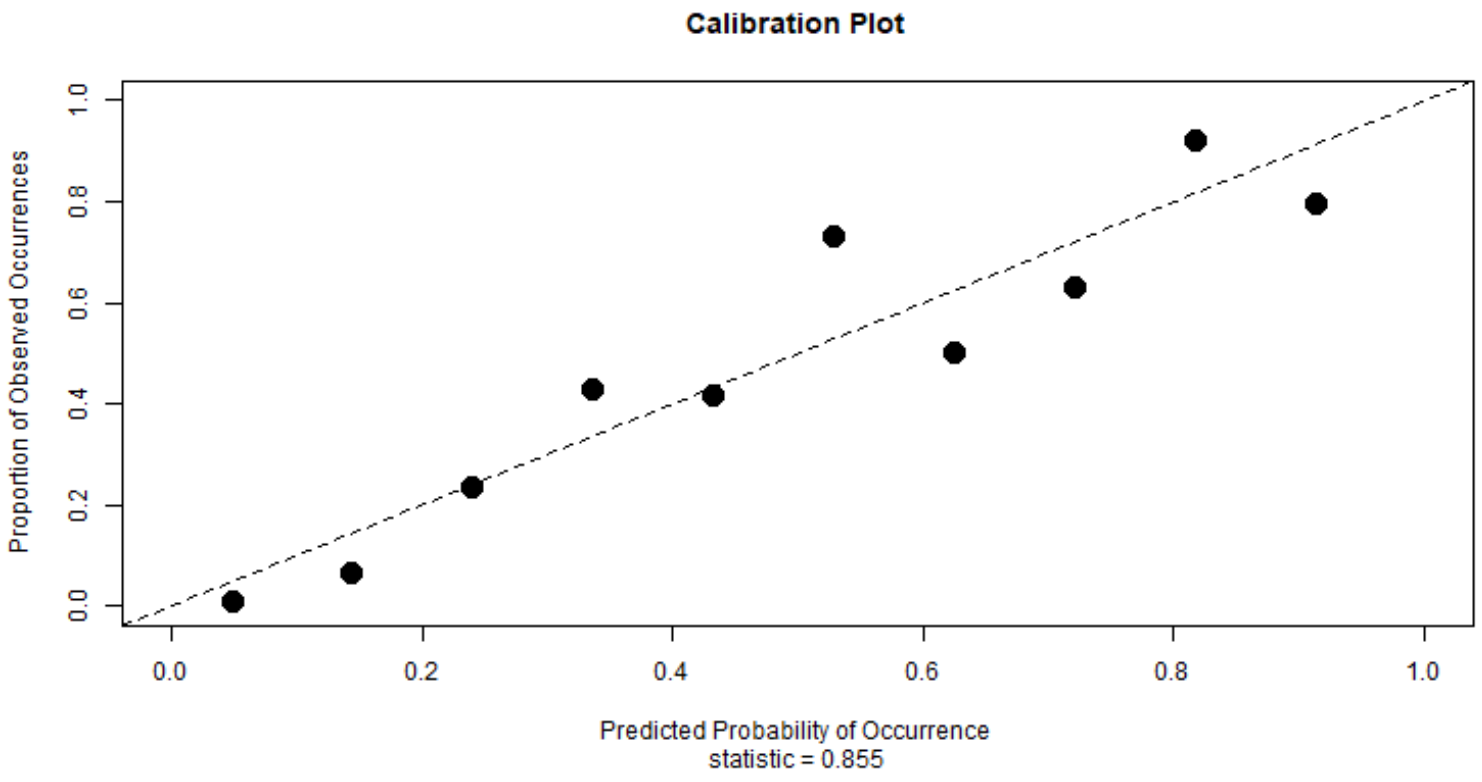

Fuente: elaboración propia 
Producido el ensamblaje de modelos, el modelo de consenso alcanzó un valor de calibración del 85 \% (Figura 6). Como se aprecia, la nube de puntos se situó casi a partes iguales sobre y bajo la línea que representa la calibración óptima. Esto significa que el modelo ensamblado o de consenso apenas sobreestima e infraestima en sus predicciones con respecto a las observaciones.

\subsection{Distribución potencial global de Xylella fastidiosa}

En este punto, presentamos la cartografía de los resultados obtenidos (Figura 7). Nuestros modelos estimaron un área de distribución potencial global para Xylella fastidiosa que abarca espacios tropicales, subtropicales y templados situados en todos los continentes (con la excepción de la Antártida), aunque con especial idoneidad en los espacios subtropicales húmedos y dominios de clima templado (Grupo C, de acuerdo con la clasificación climática de Köppen), en los que las temperaturas mínimas permiten la supervivencia del patógeno (Feil \& Purcell, 2001).

\section{Figura 7. Distribución potencial global de Xylella fastidiosa}

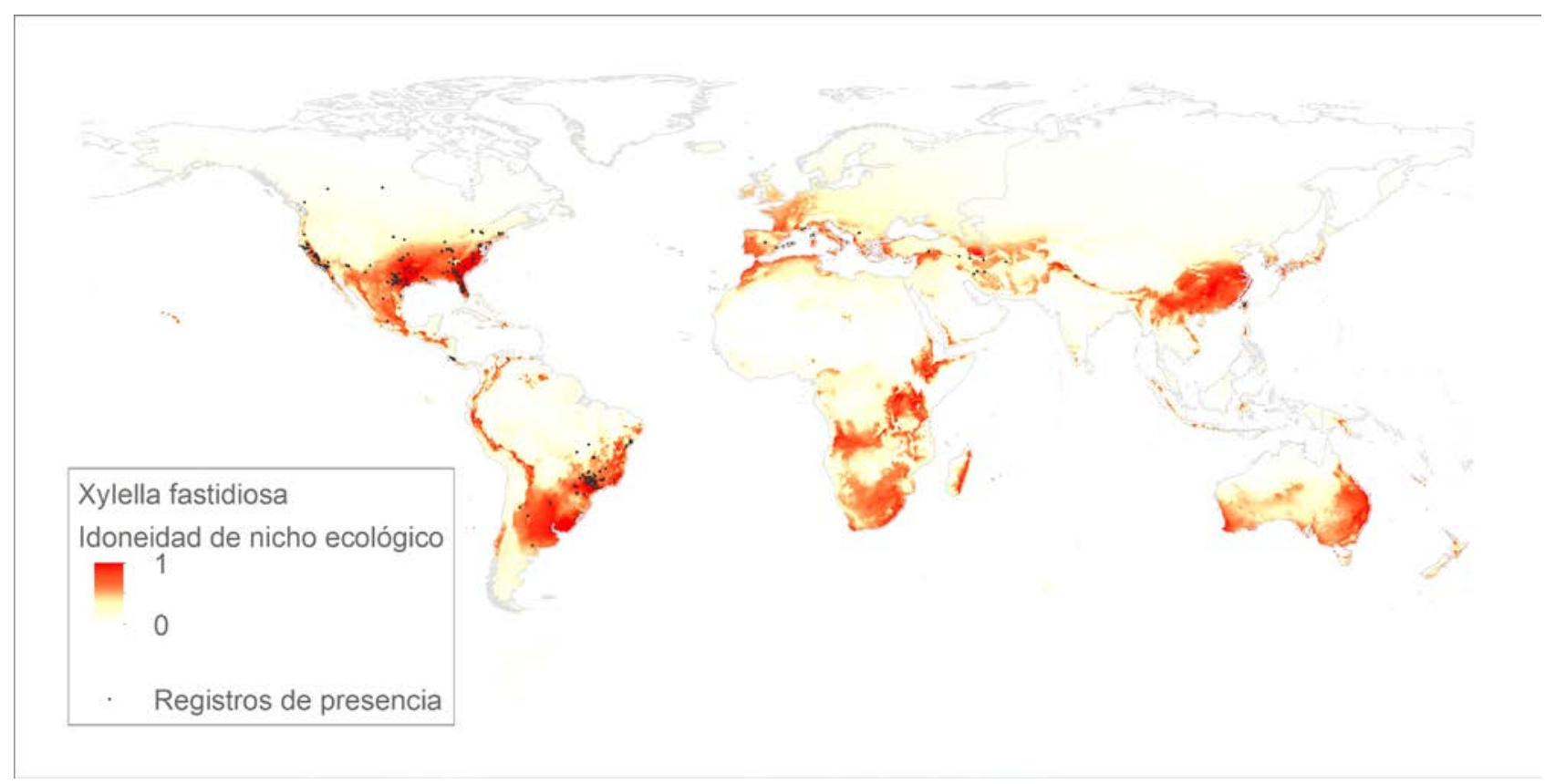

Fuente: elaboración propia

En el continente americano, origen de la diáspora de $X$. fastidiosa, es donde encontramos las áreas más favorables para el patógeno. Destacan el sureste de los Estados Unidos (regiones del Atlántico Sur, Centro Sureste, Centro Oeste y Pacífico), el sureste de Brasil (regiones Sur y Sudeste) y un importante pasillo de favorabilidad que conecta los dos hemisferios del continente, en el piedemonte de la gran cordillera. Por tanto, en este continente encontramos dos grandes factores para su establecimiento y propagación: favorabilidad y conectividad.

De acuerdo con nuestros modelos, $X$. fastidiosa también encontraría grandes áreas favorables en el sur y sudeste del continente africano, donde no se ha informado aún de la presencia del patógeno, 
lo cual no significa que la bacteria no haya llegado, dado que en muchos países africanos no existen controles fitosanitarios. Australia es otra de las extensas áreas en las que $X$. fastidiosa no ha sido detectada todavía. Sin embargo, este subcontinente presenta unas condiciones bioclimáticas muy favorables para su establecimiento en el sector oriental, donde predomina un clima templado lluvioso, similar a los climas donde la bacteria encuentra su máxima favorabilidad en América. Precisamente, en las áreas subtropicales de clima lluvioso es donde nuestros modelos estimaron el ambiente de máxima favorabilidad bioclimática para el establecimiento de $X$. fastidiosa, áreas como el sudeste del continente asiático, donde predomina el denominado clima chino (Clima Cfa, de acuerdo a Köppen) clima que parece el más favorable para el establecimiento de este patógeno.

En el continente euroasiático, se proyecta un importante corredor favorable que conecta la península Ibérica y el extremo oriental del continente asiático y que transita por zonas eminentemente subtropicales en ambas fachadas de la cuenca mediterránea y penetra por los valles de Oriente Medio y el piedemonte meridional del Himalaya, hasta llegar al extremo oriental de Asia donde encontramos el genuino clima chino. Xylella fastidiosa ha sido detectada en numerosos puntos siguiendo este pasillo, lo que sugiere que la conectividad de las áreas favorables podría explicar en parte su dispersión. En el contexto de este corredor, encontramos climas Csa y Csb (Köppen), también con un componente subtropical pero donde la estación seca coincide con el verano, a diferencia de los climas tropicales lluviosos.

Por último, apenas encontramos zonas mediadamente favorables para el establecimiento del patógeno más allá de los 40-50 de latitud. Estas las hallamos mayoritariamente en el hemisferio norte $y$, en especial, en las zonas occidentales del continente europeo, más templadas por la acción de la Corriente del Atlántico Norte. Nótese que trabajamos con algunos registros de presencia reportados en Canadá, aunque es probable que estos casos se hayan producido en condiciones muy excepcionales en el espacio y en el tiempo, de ahí que nuestros modelos no hayan proyectado favorabilidad en la vecindad de los registros de presencia reportados en estos enclaves. Las temperaturas mínimas de los climas D (Köppen) limitan la dispersión.

\subsection{Exposición de la península Ibérica e Islas Baleares a Xylella fastidiosa}

En la Figura 8, se ilustra la proyección de la distribución potencial de Xylella fastidiosa en la península Ibérica e Islas Baleares, como resultado del downscaling estadístico de los modelos calibrados y ensamblados con los registros de presencia y variables bioclimáticas de todo el mundo.

Lo primero que llama la atención es que el área de distribución potencial proyectada por los modelos coincide, en sus valores de máxima favorabilidad, con los registros de presencia de Xylella fastidiosa localizados en Islas Baleares, donde primero se ha reportado la presencia del patógeno en España. Recordamos que los modelos de distribución potencial se han calibrado con 
datos de todo el mundo y en buena parte de las iteraciones las respectivas réplicas de los modelos pueden no haber utilizado registros de presencia de esta zona.

Figura 8. Distribución potencial de Xylella fastidiosa proyectada en la península Ibérica e islas Baleares

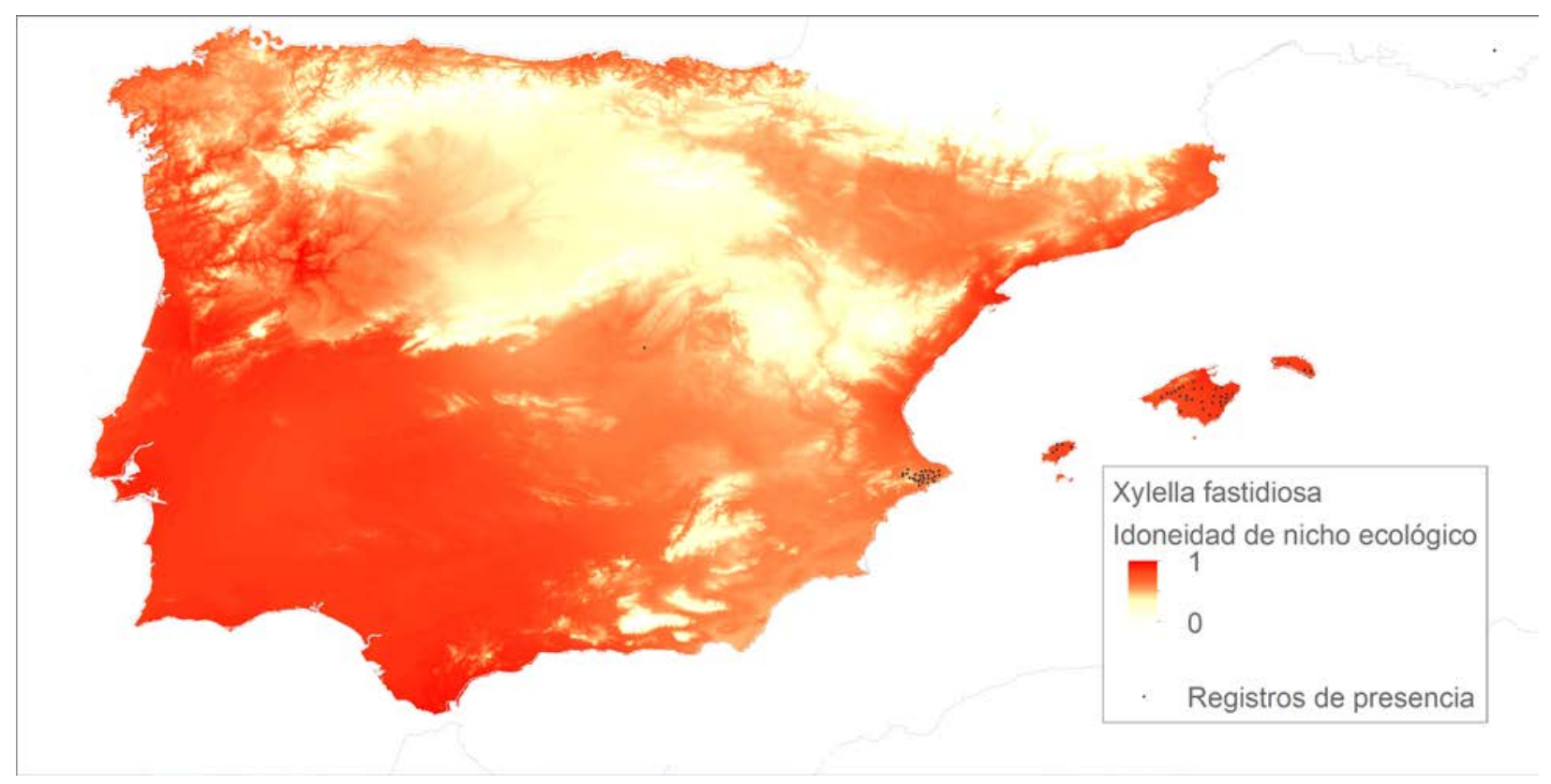

Fuente: elaboración propia

De acuerdo con nuestros modelos, la península lbérica presenta dos grandes áreas favorables para el establecimiento de Xylella fastidiosa. La primera de ellas es el cuadrante sudoccidental, caracterizado por las temperaturas elevadas y unas precipitaciones relativamente abundantes en invierno. Le sigue la fachada mediterránea, desde la costa de Alicante (donde el patógeno ya está presente) hasta la costa de Gerona. Hacia el sudeste, nuestros modelos encuentran áreas favorables, pero con valores más bajos de favorabilidad, debido a la mayor aridez que presenta este dominio. Esto mismo ocurre en la submeseta sur, en la que la favorabilidad está constreñida por otro factor limitante, la incidencia de las heladas, si bien este factor no llega a proyectar un área totalmente desfavorable. Prueba de ello es el positivo detectado en un olivar de la Comunidad de Madrid (Jeger et al., 2018). Todo lo contrario, sucede en la submeseta norte y, sobre todo, en las zonas más elevadas de los principales sistemas montañosos de la península, donde encontramos áreas desfavorables para el establecimiento de $X$. fastidiosa, especialmente por la incidencia de las bajas temperaturas.

En la Figura 9, se representa una cartografía que integra por superposición difusa el conjunto de drivers o factores geográficos que pueden facilitar la introducción y/o propagación de Xylella fastidiosa. Esta cartografía es producto de funciones de pertenencia difusa (Fuzzy Membership) aplicadas a cada uno de los factores o drivers y de la superposición difusa del conjunto. 
De acuerdo con los drivers, las áreas más expuestas a la entrada y dispersión del patógeno son, fundamentalmente, los espacios interiores próximos a la costa en los que predominan las actividades agrarias, soportan densidades de población intermedias y se hallan bien comunicados. Por el contrario, los vacíos demográficos de las áreas del interior de la península constituyen los espacios menos expuestos a la entrada y propagación de Xylella fastidiosa.

Figura 9. Integración drivers y favorabilidad para la dispersión de Xylella fastidiosa

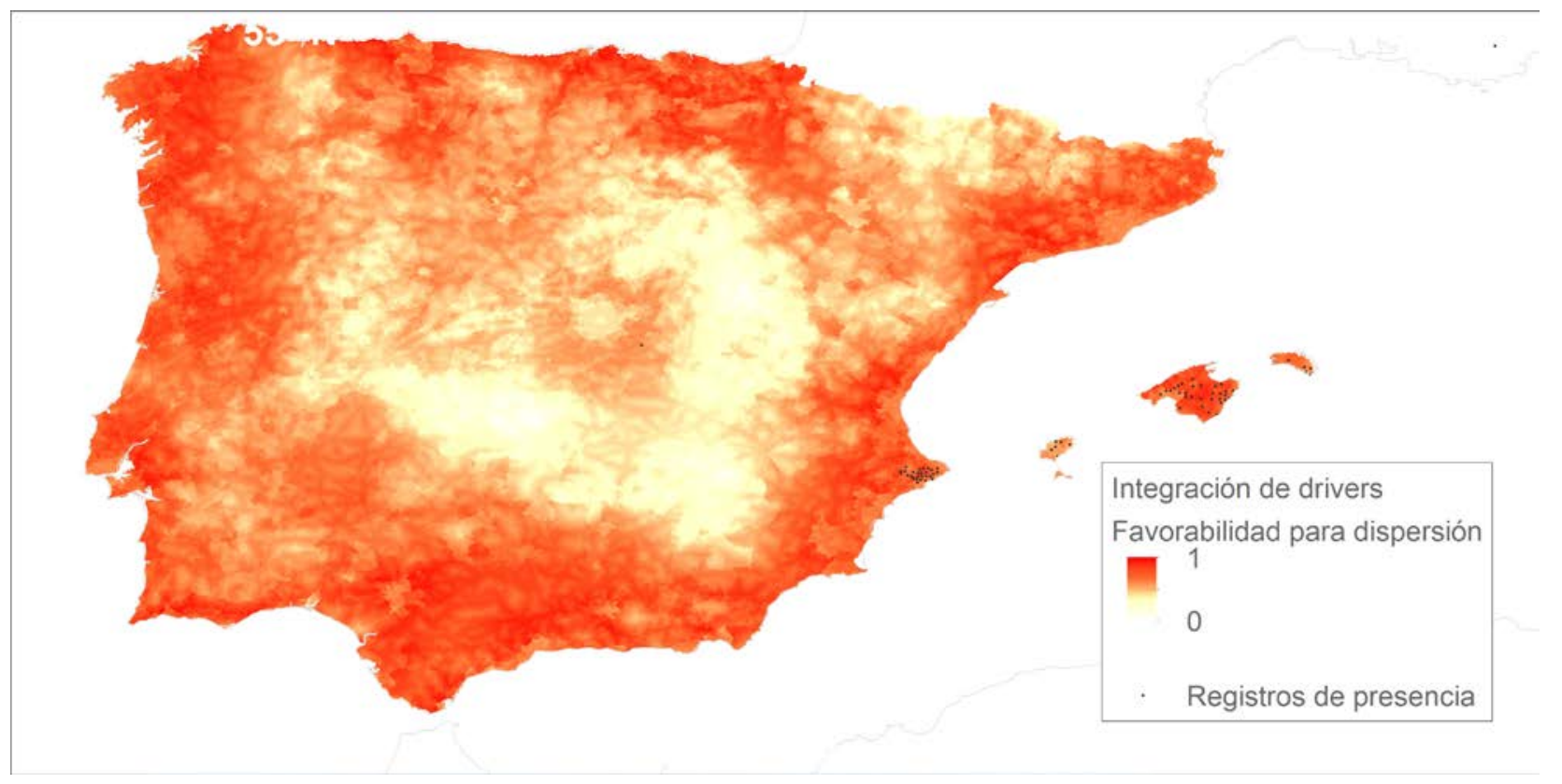

Fuente: elaboración propia

Figura 10. Modelo de exposición de la península Ibérica e islas Baleares a Xylella fastidiosa

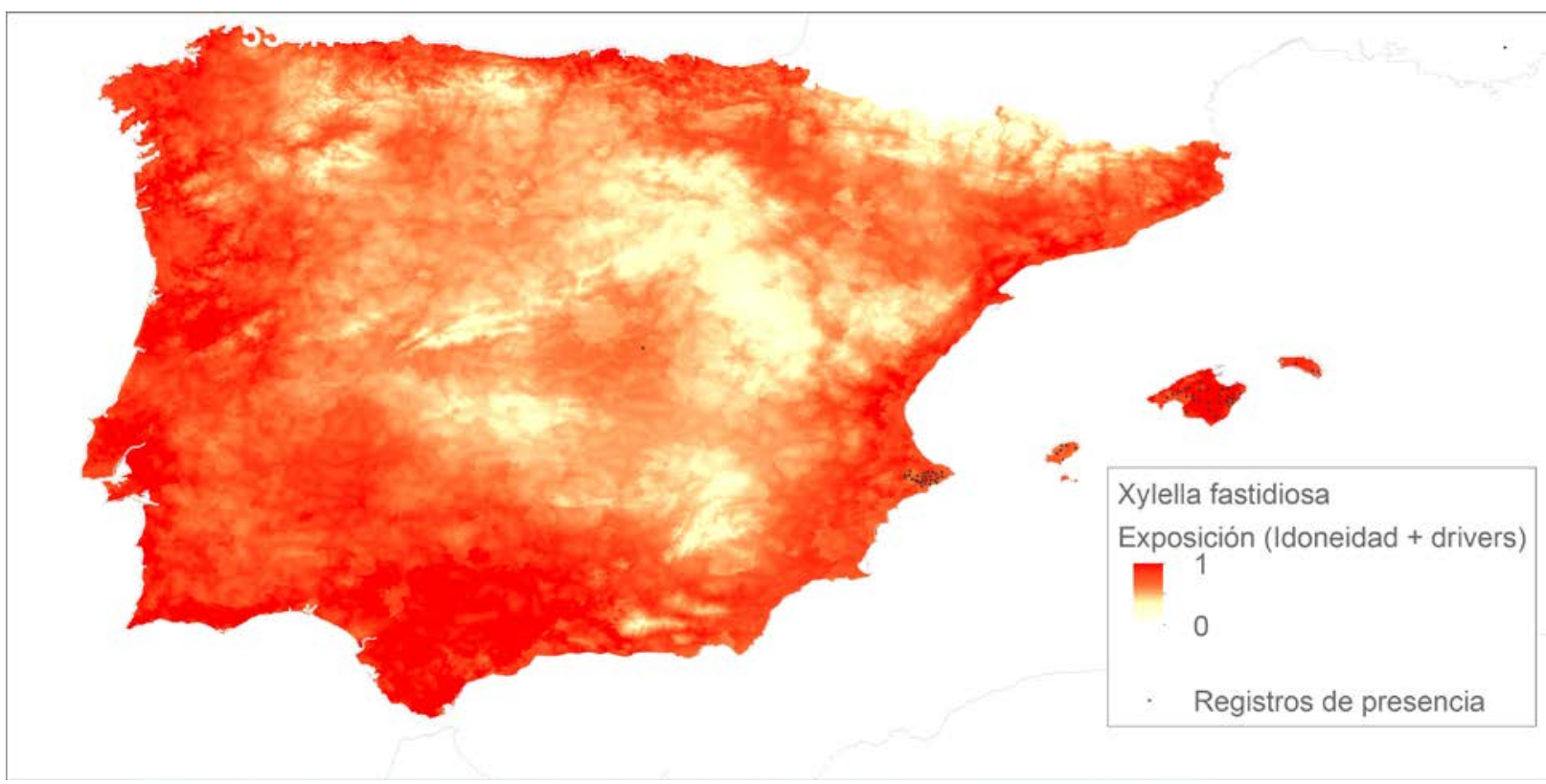

Fuente: elaboración propia 
Por último, en la Figura 10 se ilustra la cartografía final que representa la exposición de la península Ibérica e Islas Baleares a la entrada y / o propagación de Xyella fastidiosa. Esta cartografía es producto de la superposición difusa de los resultados representados en las figuras 8 y 9.

Concluyendo, de acuerdo con nuestros modelos, las áreas más expuestas a la propagación de Xylella fastidiosa son fundamentalmente las situadas en las zonas periféricas y más deprimidas del conjunto del área de estudio, incluida la costa del norte de la península lbérica. Si bien, encontramos una máxima exposición en el suroeste de la península Ibérica, Levante e Islas Baleares.

\section{Discusión}

\subsection{Posibilidades y limitaciones de los modelos}

La inferencia estadística aporta una base matemática, fundamentada en la teoría de nichos ecológicos, para generalizar y proyectar modelos más allá del área de calibración (Franklin, 1995; Gallien et al., 2010; Guisan et al., 2017; Peterson et al., 2011).

Sin embargo, no son pocas las investigaciones que se realizan sólo con registros de presencia localizados en el área donde ha comenzado a producirse la invasión, lo cual introduce un sesgo de muestreo fundamental puesto que podríamos estar omitiendo rangos de tolerancia ambiental que las especies invasoras pueden soportar en otros lugares donde ya está presente (Václavík \& Meentemeyer, 2012). En este sentido, la transferibilidad de modelos entre nichos de calibración (área nativa) y proyección (área invadible) también resultan problemáticas (Zhu \& Peterson, 2017).

Con respecto al primer caso, un grupo de investigadores italianos publicó un artículo sobre la distribución potencial de Xylella fastidiosa en Italia (Bosso et al., 2016). En este trabajo, los autores calibran un modelo de máxima entropía con registros de presencia localizados únicamente en la región italiana de Apulia, donde el patógeno está presente desde el año 2013, y predicciones proyectadas hacia el conjunto de Italia, y obtuvieron un AUC del 0,971. En otro trabajo, los mismos autores hicieron lo propio proyectando las predicciones para el conjunto de la Cuenca Mediterránea (Bosso et al., 2016). En ambos artículos, estos autores se refieren a una "excelente capacidad predictiva de los modelos" y una "fuerte validación estadística de los modelos". En un trabajo posterior (Gutiérrez Hernández \& García, 2018), en el que desarrollamos diferentes modelos de distribución potencial de X. fastidiosa en la península Ibérica e islas Baleares, basado en los registros de presencia del citado archipíelago, señalamos las limitaciones de tales afirmaciones. Los modelos de nicho ecológico basados en datos bioclimáticos infraestiman las distribuciones potenciales cuando interviene el ser humano como vector de las especies, pues proyectan distribuciones demasiado ajustadas, especialmente cuando se emplean registros de presencia localizados en una región muy característica (Ramírez-Albores et al., 2016). 
A menudo se emplea el término validación con un uso que no es el estrictamente correcto, porque es imposible validar íntegramente el modelo numérico de un sistema natural (Oreskes et al., 1994). Insistimos en que el AUC es una métrica que se emplea para medir la capacidad discriminante o el grado de ajuste de los modelos. Cuando se evalúa la capacidad discriminante de un modelo, no se trata de buscar el valor más elevado, porque es relativamente sencillo encontrarlo -basta con ampliar el área de estudio-, sino de justificar cómo y por qué se ha diseñado el área de calibración y cuál es el contenido y sentido con el que se utiliza el AUC.

Por otra parte, las métricas discriminantes quizás no sean las más adecuadas para trabajar con registros incompletos de especies invasoras en el nuevo rango de invasión cuando estas se encuentran en los estadios iniciales. Por eso, en el presente trabajo, además de emplear una medida de ajuste como el AUC, implementamos también una medida de calibración.

Las especies invasoras no se encuentran en equilibrio con las condiciones del medio en los estadios iniciales de las invasiones biológicas (Václavík \& Meentemeyer, 2012). Conviene esclarecer los conceptos y las limitaciones de unos modelos que a menudo distan mucho de ser infalibles (Jiménez-Valverde et al., 2008). Por ejemplo, es necesario que el extent o área de calibración de los modelos esté plenamente justificado (Barve et al., 2011). Algunos autores recomiendan trabajar con el conjunto más amplio de datos disponible sobre la especie invasora, tanto en el rango nativo de su distribución como en el área dónde aparece como organismo invasor (Jiménez-Valverde et al., 2011). El problema está en que no siempre están disponibles esos datos y en muchos casos las administraciones públicas no facilitan el acceso a los mismos, lo que dificulta el desarrollo de trabajo cuando éste resulta más necesario, esto es, antes de que una potencial especie invasora haya irrumpido y producido un daño irreparable.

Este fue el motivo principal por el que decidimos trabajar con los registros de presencia de Xylella fastidiosa de todo el mundo, porque se trata de modelizar el más amplio rango de tolerancias ambientales posible. Y aún en este supuesto, hay especies invasoras que pueden sobrevivir más allá de su rango de tolerancias ambientales conocido (Parker et al., 2013). Desde el punto de vista biogeográfico, los procesos de especiación han estado limitados por barreras biogeográficas (Barve et al., 2011). Esto viene a significar que las especies tenderán a estar adaptadas a las condiciones ambientales de su área de distribución, pero no invalida el supuesto de que una especie dada pudiera soportar un rango de tolerancias ambientales más amplio cuando desaparece el efecto de barrera biogeográfica, hecho que concurre cuando las actividades humanas movilizan organismos de un lugar a otro del planeta. Complementariamente, los modelos de nicho serían más eficaces desde el punto de vista de la predicción de las invasiones biológicas si contemplaran, además, los nichos ecológicos y los patrones de dispersión de los organismos vectores que 
dispersan los patógenos (Cruaud et al., 2018), en tanto que estos pueden facilitar una rápida propagación del patógeno en la península (Lopes et al., 2014; Morente et al., 2018).

\subsection{Una aproximación multidisciplinar: aportaciones de la Geografía}

Superadas -en la medida de las posibilidades- las limitaciones de los modelos de nicho ecológico, estimamos la exposición de la península Ibérica con respecto a Xylella fastidiosa. Lo hicimos integrando mediante operaciones de superposición difusa el conjunto de drivers o factores geográficos que pueden favorecer la introducción de la especie invasora movilizada por las actividades humanas.

Hay que tener presente que el modelo de nicho nos puede informar acerca de hasta dónde puede llegar una especie en función de su rango de tolerancias ambientales. Esta información es necesaria, en tanto que representa una causa necesaria, esto es, si el factor ecológico es desfavorable para un organismo exótivo, la invasión no ocurrirá. Pero necesitamos conocer, además, las condiciones o causas suficientes, que combinadas con las causas necesarias desencadenan los factores de riesgo. En este sentido, la evidencia empírica manifiesta el poder explicativo de los factores geográficos que hemos denominado drivers, en tanto que suelen ser los gradientes de proximidad, de densidad de población o intensidad de los flujos los que suelen estar más relacionados con movimientos más intensos de material biológico. Por un lado, respaldamos esta información basándonos en investigaciones previas (Dalmazzone \& Giaccaria, 2014; Packer et al., 2017; Seebens et al., 2015). Por otro, hemos demostrado empíricamente cómo allí donde hay registros de Xylellla fastidiosa (Islas Baleares, Alicante) se asocia una alta idoneidad ecológica con una baja impedancia (resistencia) del medio geográfico.

No cabe duda de que las invasiones biológicas están revolucionando el concepto de Biogeografía, y que, entendida esta disciplina como una ciencia geográfica, hemos de reconsiderar que la distribución geográfica de las especies en el Antropoceno va mucho más allá de lo que expone el clásico argumentario acerca de las tolerancias ambientales y los procesos de dispersión de los organismos de la biosfera (Gallardo \& Vila, 2019). A pesar de las críticas, los modelos de nicho ecológico siguen demostrando su utilidad en la predicción de invasiones biológicas (Barbet-Massin et al., 2018), aunque infraestiman la distribución potencial de los organismos exóticos, especialmente en casos donde intervienen huespedes y vectores, cuyas tolerancias ambientales amplían el espectro de la incertidumbre (Escobar \& Craft, 2016). A los vectores naturales, como geógrafos, debemos añadir el pricipal vector: el ser humano (Banks et al., 2015).

La estimación del riesgo de exposición a la llegada y propagación de especies invasoras supone un auténtico desafío metodológico que necesariamente requiere una aproximación multidisciplinar (Ricciardi et al., 2017). En el seno de las investigaciones geográficas urge también una reconducción de alguno de sus campos de conocimiento más allá de la Biogeografía (Murray et 
al., 2018); es necesario, por citar uno de sus campos tradicionales, un replanteamiento de la Geografía Agraria, sumida en una profundo declive por la obsolescencia de sus intereses, enfoques y estrategias metodológicas, pero cuyo campo de estudio la sitúa ante un abanico de posibilidades infinitas (Katinas \& Crisci, 2018; Robinson, 2018). Otra geografía emergente, la geografía de los espacios y destinos turísticos, tiene frente a sí un campo de estudio apenas explorado, aquel que relaciona turismo y propagación de especies exóticas. La evidencia demuestra, por ejemplo, que la abundancia y riqueza de especies exóticas es significativamente mayor en los sitios en los que se realizan actividades turísticas (Anderson et al., 2015).

En conclusión, la nueva Biogeografía debe priorizar el estudio de los riesgos biológicos vinculados con la globalización (Cope et al., 2017) y ocuparse también del estado de salud de la Tierra (Murray et al., 2018), prestando especial atención a la incidencia del cambio climático en la redistribución natural y antrópica de la biodiversidad (Wang et al., 2017), y priorizando la planificación y la prevención, dado que los estadios iniciales de las invasiones biológicas son los que concentran los mayores impactos en los ecosistemas y agrosistemas (Závorka et al., 2018). En el marco global del Antropoceno, se requiere una acción colectiva y coordinada que minimice los principales riesgos ambientales de nuestra época (Steffen et al., 2018).

\section{Conclusiones}

En este trabajo hemos desarrollado modelos de nicho ecológico para estimar la distribución potencial global de Xylella fastidiosa. Ensamblamos dichas estimas a escala regional (península Ibérica e Islas Baleares) con drivers que pueden favorecer los procesos de dispersión observados en el patógeno.

A escala global, nuestros modelos han estimado una amplia distribución potencial de Xylella fastidiosa en latitudes medias, con valores de favorabilidad máximos en áreas con predominio de climas templados y húmedos. A nivel regional, estimamos que existe un gran potencial bioclimático para el establecimiento de $X$. fastidiosa en las zonas periféricas de la península Ibérica y Baleares y, especialmente, en el suroeste de la península y en la fachada mediterránea. En general, las áreas más expuestas a la entrada y dispersión del patógeno se corresponden con los espacios interiores próximos a la costa en los que predominan las actividades agrarias, soportan densidades de población intermedias y se hallan bien comunicados.

Tanto los resultados obtenidos como la metodología aplicada representan una novedad. Por un lado, se trata de la primera estima global de distribución potencial de Xylella fastiosa basada en un ensamblaje de modelos. Por otro lado, es la primera vez que se integran la modelización de nichos ecológicos y las técnicas de evaluación multicriterio, basadas en funciones de pertenencia y 
superposición borrosas, para representar un modelo de exposición regional a un organismo exótico como X. fastidiosa.

Los resultados evidencian la enorme importancia y utilidad de la información espacial y sitúa a la geografía (y a la Geografía, como disciplina) en el centro de la investigación de los procesos de contagio espacial, en el contexto de la gestión de los riesgos biológicos. En este sentido, futuros trabajos deberían avanzar en el terreno de la caracterización y discusión de la influencia de los principales drivers involucrados en la propagación de las especies exóticas, más allá de la estimación de las distribuciones potenciales basada en los modelos de nicho ecológico. En el Antropoceno, la estimación fidedigna de los riesgos biológicos trasciende la teoría de la probabilidad y se interna en complejo mundo de la teoría de los conjuntos borrosos.

Declaración responsable: Las/os autoras/es declaran que no existe ningún conflicto de interés en relación con la publicación de este artículo. Las tareas se han distribuido de la siguiente manera: Oliver Gutiérrez Hernández, diseño de la investigación, análisis de datos y redacción del manuscrito original; Luis V. García: revisión crítica, correcciones y aportaciones sobre aspectos relacionados con la biología, el análisis de datos y la redacción. 


\section{Bibliografía}

Almeida, R. P. P., Coletta-Filho, H. D., \& Lopes, J. R. S. (2014). Xylella fastidiosa. In Manual of Security Sensitive Microbes and Toxins (pp. 841-850). Boca Raton (Florida, US): CRC Press.

Almeida, R. P. P., \& Purcell, A. H. (2003). Biological Traits of Xylella fastidiosa Strains from Grapes and Almonds. Applied and Environmental Microbiology, 69(12), 7447-7452. https://doi.org/10.1128/AEM.69.12.7447-7452.2003

Anderson, L. G., Rocliffe, S., Haddaway, N. R., \& Dunn, A. M. (2015). The role of tourism and recreation in the spread of non-native species: A systematic review and meta-analysis. PLOS ONE, 10(10), 1-15. https://doi.org/10.1371/journal.pone.0140833

Araújo, W. L., Marcon, J., Maccheroni, W., Van Elsas, J. D., Van Vuurde, J. W. L., \& Azevedo, J. L. (2002). Diversity of endophytic bacterial populations and their interaction with Xylella fastidiosa in citrus plants. Applied and Environmental Microbiology, 68(10), 4906-4914. https://doi.org/10.1128/AEM.68.10.4906-4914.2002

Ayala Carcedo, F. J., \& Olcina Cantos, J. (2002). Riesgos naturales. Barcelona: Ariel.

Banks, N. C., Paini, D. R., Bayliss, K. L., \& Hodda, M. (2015). The role of global trade and transport network topology in the human-mediated dispersal of alien species. Ecology Letters, 18(2), 188-199. https://doi.org/10.1111/ele.12397

Barbet-Massin, M., Rome, Q., Villemant, C., \& Courchamp, F. (2018). Can species distribution models really predict the expansion of invasive species? PLoS ONE, 13(3), 1-14. https://doi.org/10.1371/journal.pone.0193085

Barve, N., Barve, V., Jiménez-Valverde, A., Lira-Noriega, A., Maher, S. P., Peterson, A. T., \& Villalobos, F. (2011). The crucial role of the accessible area in ecological niche modeling and species distribution modeling. Ecological Modelling, 222(11), 1810-1819. https://doi.org/10.1016/j.ecolmodel.2011.02.011

Benedetti, Y., \& Morelli, F. (2017). Spatial mismatch analysis among hotspots of alien plant species, road and railway networks in Germany and Austria. PLoS ONE, 12(8). https://doi.org/10.1371/journal.pone.0183691

Bertelsmeier, C., Ollier, S., Liebhold, A., \& Keller, L. (2017). Recent human history governs global ant invasion dynamics. Nature Ecology and Evolution, 1(7). https://doi.org/10.1038/s41559-017$\underline{0184}$

Bosso, L., Di Febbraro, M., Cristinzio, G., Zoina, A., \& Russo, D. (2016). Shedding light on the effects of climate change on the potential distribution of Xylella fastidiosa in the Mediterranean basin. Biological Invasions, 18(6), 1759-1768. https://doi.org/10.1007/s10530-016-1118-1 
Bosso, L., Russo, D., Di Febbraro, M., Cristinzio, G., \& Zoina, A. (2016). Potential distribution of Xylella fastidiosa in Italy: a maximum entropy model. Phytopathologia Mediterranea, 55(1), 62-72. https://doi.org/10.14601/Phytopathol

Bucci, E. M. (2018). Xylella fastidiosa, a new plant pathogen that threatens global farming: Ecology, molecular biology, search for remedies. Biochemical and Biophysical Research Communications, 502(2), 173-182. https://doi.org/10.1016/j.bbrc.2018.05.073

Capinha, C., Essl, F., Seebens, H., Moser, D., \& Pereira, H. M. (2015). The dispersal of alien species redefines biogeography in the Anthropocene. Science, 348(6240), 1248-1251. https://doi.org/10.1126/science.aaa8913

Carlucci, A., Lops, F., Marchi, G., Mugnai, L., \& Surico, G. (2013). Has Xylella fastidiosa "chosen" olive trees to establish in the mediterranean basin? Phytopathologia Mediterranea, 52(3), 541-544. https://doi.org/doi: 10.14601/Phytopathol_Mediterr-13623

Chatterjee, S., Almeida, R. P. P., \& Lindow, S. (2008). Living in two Worlds: The Plant and Insect Lifestyles of Xylella fastidiosa. Annual Review of Phytopathology, 46(1), 243-271. https://doi.org/10.1146/annurev. phyto.45.062806.094342

Colautti, R., Colautti, R., Parker, J. D., Cadotte, M. W., Pyšek, P., Brown, C. S., \& Richardson, D. (2014). Quantifying the invasiveness of species. NeoBiota, 21, 7-27. https://doi.org/10.3897/neobiota.21.5310

Cope, R. C., Ross, J. V., Wittmann, T. A., Watts, M. J., \& Cassey, P. (2017). Predicting the Risk of Biological Invasions Using Environmental Similarity and Transport Network Connectedness. Risk Analysis. https://doi.org/10.1111/risa. 12870

Cruaud, A., Gonzalez, A. A., Godefroid, M., Nidelet, S., Streito, J. C., Thuillier, J. M., \& Rasplus, J. Y. (2018). Using insects to detect, monitor and predict the distribution of Xylella fastidiosa: a case study in Corsica. Scientific Reports, 8(1). https://doi.org/10.1038/s41598-018-33957-z

Dalmazzone, S., \& Giaccaria, S. (2014). Economic drivers of biological invasions: A worldwide, bio-geographic analysis. Ecological Economics, 105, 154-165. https://doi.org/10.1016/j.ecolecon.2014.05.008

De Marco, P., \& Nóbrega, C. C. (2018). Evaluating collinearity effects on species distribution models: An approach based on virtual species simulation. PLoS ONE, 13(9). https://doi.org/10.1371/journal.pone.0202403

Delbianco, A., Czwienczek, E., Pautasso, M., Kozelska, S., Monguidi, M., \& Stancanelli, G. (2019). A new resource for research and risk analysis: the updated European Food Safety Authority 
database of Xylella spp. host plant species. Phytopathology. https://doi.org/10.1094/PHYTO-09$\underline{18-0343-\mathrm{A}}$

Dormann, C. F., Elith, J., Bacher, S., Buchmann, C., Carl, G., Carré, G., \& Lautenbach, S. (2013). Collinearity: A review of methods to deal with it and a simulation study evaluating their performance. Ecography, 36(1), 027-046. https://doi.org/10.1111/j.1600-0587.2012.07348.x

Eastman, J. R. (2015). TerrSet: Geospatial Monitoring and Modeling Software (Software Manual). Worcester MA (USA): Clark University. More information at https://clarklabs.org/terrset/

Eastman, R. (1999). Multi-criteria evaluation and GIS. Geographical Information Systems, 1(1), 493-502.

Efron, B. (1981). Nonparametric estimates of standard error: The jackknife, the bootstrap and other methods. Biometrika, 68(3), 589-599.

Elith, J. (2017). Predicting distributions of invasive species. In A. P. Robinson, T. Walshe, M. A. Burgman \& M. Nunn (Eds.), Invasive Species: Risk Assessment and Management (pp. 93-129). Cambridge University Press. https://doi.org/10.1017/9781139019606.006

Escobar, L. E., \& Craft, M. E. (2016). Advances and limitations of disease biogeography using ecological niche modeling. Frontiers in Microbiology, 7(AUG), 1-21. https://doi.org/10.3389/fmicb.2016.01174

Essl, F., Bacher, S., Blackburn, T. M., Booy, O., Brundu, G., Brunel, S., \& Jeschke, J. M. (2015). Crossing Frontiers in Tackling Pathways of Biological Invasions. BioScience, 65(8), 769-782. https://doi.org/10.1093/biosci/biv082

Feil, H., \& Purcell, A. H. (2001). Temperature-Dependent Growth and Survival of Xylella fastidiosa in Vitro and in Potted Grapevines. Plant Disease, 85(12), 1230-1234. https://doi.org/10.1094/PDIS.2001.85.12.1230

Fick, S., \& Hijmans, R. . (2017). Worldclim 2: New 1-km spatial resolution climate surfaces for global land areas. International Journal of Climatology, 37(12), 4302-4315. https://doi.org/10.1002/joc.5086

Fielding, A. H., \& Bell, J. F. (1997). A review of methods for the assessment of prediction errors in conservation presence/absence models. Environmental Conservation, 24(1), 38-49.

Franklin, J. (1995). Predictive vegetation mapping: geographic modelling of biospatial patterns in relation to environmental gradients. Progress in Physical Geography, 19, 474-499.

Franklin, J. (2009). Mapping Species Distributions: Spatial Inference and Prediction (Ecology, Biodiversity and Conservation). New York: Cambridge University Press. 
Friedman, J. H. (1991). Multivariate Adaptive Regression Splines. The Annals of Statistics, 19(1), 167. https://doi.org/10.1214/aos/1176347963

Gallardo, B., \& Vila, L. (2019). La influencia humana, clave para entender la Biogeografía de especies invasoras en el Antropoceno. Cuadernos de Investigación Geográfica, 45 (Unpublished). https://doi.org/http://doi.org/10.18172/cig.3627

Gallien, L., Münkemüller, T., Albert, C. H., Boulangeat, I., \& Thuiller, W. (2010). Predicting potential distributions of invasive species: where to go from here? Diversity and Distributions, 16(3), 331-342.

Giampetruzzi, A., Velasco-Amo, M. P., Marco-Noales, E., Montes-Borrego, M., Román-Écija, M., Navarro, I., \& Landa, B. B. (2018). Draft Genome Resources of Two Strains ("ESVL" and "IVIA5901") of Xylella fastidiosa Associated with Almond Leaf Scorch Disease in Alicante, Spain. Phytopathology, (October), PHYTO-09-18-032. https://doi.org/10.1094/PHYTO-09-18-0328-A

Grosholz, E. D. (2018). New sources for the emergence of new invaders. Proceedings of the $\begin{array}{llll}\text { National Academy } & \text { 2270-2271. }\end{array}$ https://doi.org/10.1073/pnas. 1800257115

Guisan, A., Thuiller, W., \& Zimmermann, N. E. (2017). Habitat Suitability and Distribution Models: With Applications in R. Cambridge: Cambridge University Press. https://doi.org/10.1017/9781139028271

Guisan, A., \& Zimmermann, N. E. (2000). Predictive habitat distribution models in ecology. Ecological Modelling, 135(2-3), 147-186.

Guisande González, C., Vaamonde Liste, A., \& Barreiro Felpeto, A. (2013). Tratamiento de datos con R, STATISTICA y SPSS. Madird: Ediciones Díaz de Santos.

Gutiérrez Hernández, O., Cámara-Artigas, R., Senciales-González, J. M., \& García, L. V. (2018). Modelos predictivos en Biogeografía: aplicación para la modelización de nichos ecológicos en Geografía Física applying ecological niche modelling in Physical Geography. Boletin de La Asociacion de Geógrafos Espanoles, 78, 88-126. http://dx.doi.org/10.21138/bage.2395

Gutiérrez Hernández, O., \& García, L. V. (2018). Incidencia de Xylella fastidiosa en las Islas Baleares y distribución potencial en la península ibérica. Investigaciones Geográficas, 69, 55-72. https://doi.org/10.14198/INGEO2018.69.04

Hopkins, D. L. (1989). Xylella fastidiosa: Xylem-Limited Bacterial Pathogen of Plants. Annual Review of Phytopathology, 27, 271-290. https://doi.org/10.1146/annurev.py.27.090189.001415 
Jackson, D. A. (1993). Stopping Rules in Principal Components Analysis: A Comparison of Heuristical and Statistical Approaches. Ecology, 74(8), 2204-2214. https://doi.org/10.11400/kekkaku1923.50.8_229

Janse, J. D., \& Obradovic, A. (2010). Xylella fastidiosa: Its biology, diagnosis, control and risks. Journal of Plant Pathology. https://doi.org/10.4454/JPP. V92I1SUP.2504

Jeger, M., Caffier, D., Candresse, T., Chatzivassiliou, E., Dehnen-Schmutz, K., Gilioli, G., \& Bragard, C. (2018). Updated pest categorisation of Xylella fastidiosa. EFSA Journal, 16(7). https://doi.org/10.2903/j.efsa.2018.5357

Jiang, H., \& Eastman, J. R. (2000). Application of fuzzy measures in multi-criteria evaluation in GIS. International Journal of Geographical Information Science, 14(2), 173-184. https://doi.org/10.1080/136588100240903

Jiménez-Valverde, A., Lobo, J. M., \& Hortal, J. (2008). Not as good as they seem: the importance of concepts in species distribution modelling. Diversity and Distributions, 14(6), 885-890.

Jiménez-Valverde, A., Peterson, A. T., Soberón, J., Overton, J. M., Aragón, P., \& Lobo, J. M. (2011). Use of niche models in invasive species risk assessments. Biological Invasions, 13(12), 2785-2797.

Katinas, L., \& Crisci, J. V. (2018). Agriculture Biogeography: An emerging discipline in search of a conceptual framework. Progress in Physical Geography, 42(4), 513-529. https://doi.org/10.1177/0309133318776493

Kottek, M., Grieser, J., Beck, C., Rudolf, B., \& Rubel, F. (2006). World Map of Köppen-Geiger Climate Classification. Meteorologische Zeitschrift, 15, 259-263. https://doi.org/10.1127/0941$\underline{2948 / 2006 / 0130}$

Landa, B., Marco-Noales, E., \& López, M. M. (2017). Enfermedades causadas por la bacteria Xylella fastidiosa. Cajamar Caja Rural.

Lima, J. E. O. De, Miranda, V. S., Hartung, J. S., Brlansky, R. H., Coutinho, A., Roberto, S. R., \& Carlos, E. F. (1998). Coffee Leaf Scorch Bacterium: Axenic Culture, Pathogenicity and Comparison with Xylella fastidiosa of Citrus. Plant Disease, 82(1), 94-97. https://doi.org/10.1094/PDIS. 1998.82.1.94

Lobo, J. M., Jiménez-Valverde, A., \& Hortal, J. (2010). The uncertain nature of absences and their importance in species distribution modelling. Ecography, 33(1), 103-114.

Lobo, J. M., Jiménez-Valverde, A., \& Real, R. (2008). AUC: a misleading measure of the performance of predictive distribution models. Global Ecology and Biogeography, 17(2), 145151. 
Loconsole, G., Potere, O., Boscia, D., Altamura, G., Djelouah, K., Elbeaino, T., \& Saponari, M. (2014). Detection of Xylella fastidiosa in olive trees by molecular and serological methods. Journal of Plant Pathology. hittps://doi.org/10.4454/JPP. V9611.041

Lopes, J. R. S., Landa, B. B., \& Fereres, A. (2014). A survey of potential insect vectors of the plant pathogenic bacterium Xylella fastidiosa in three regions of Spain. Spanish Journal of Agricultural Research, 12(3), 795-800. https://doi.org/10.5424/sjar/2014123-5613

Mang, S. M., Frisullo, S., Elshafie, H. S., \& Camele, I. (2016). Diversity evaluation of Xylella fastidiosa from infected olive trees in Apulia (Southern Italy). Plant Pathology Journal, 32(2), 102111. https://doi.org/10.5423/PPJ.OA.08.2015.0153

Mansfield, J., Genin, S., Magori, S., Citovsky, V., Sriariyanum, M., Ronald, P., \& Foster, G. D. (2012). Top 10 plant pathogenic bacteria in molecular plant pathology. Molecular Plant Pathology, 13(6), 614-629. hitps://doi.org/10.1111/j.1364-3703.2012.00804.x

Meurisse, N., Rassati, D., Hurley, B. P., Brockerhoff, E. G., \& Haack, R. A. (2018). Common pathways by which non-native forest insects move internationally and domestically. Journal of Pest Science. https://doi.org/10.1007/s10340-018-0990-0

Miraldo, A., Li, S., Borregaard, M. K., Flórez-rodríguez, A., Gopalakrishnan, S., Rizvanovic, M., \& Nogués-bravo, D. (2016). An Anthropocene map of genetic diversity. Science, 353(6307), 15321535. https://doi.org/10.1126/science.aaf4381

Montz, B. E., \& Tobin, G. A. (2011). Natural hazards: An evolving tradition in applied geography. Applied Geography, 31(1), 1-4. https://doi.org/10.1016/j.apgeog.2010.06.005

Morente, M., Cornara, D., Moreno, A., \& Fereres, A. (2018). Continuous indoor rearing of Philaenus spumarius, the main European vector of Xylella fastidiosa. Journal of Applied Entomology, 142(9), 901-904. https://doi.org/10.1111/jen.12553

Morente, M., Cornara, D., Plaza, M., Durán, J., Capiscol, C., Trillo, R., Fereres, A. (2018). Distribution and Relative Abundance of Insect Vectors of Xylella fastidiosa in Olive Groves of the Iberian Peninsula. Insects, 9(4), 175. https://doi.org/10.3390/insects9040175

Murray, K. A., Olivero, J., Roche, B., Tiedt, S., \& Guégan, J. F. (2018). Pathogeography: leveraging the biogeography of human infectious diseases for global health management. Ecography, 41(9), 1411-1427. https://doi.org/10.1111/ecog.03625

Murray, K. A., Preston, N., Allen, T., Zambrana-Torrelio, C., Hosseini, P. R., \& Daszak, P. (2015). Global biogeography of human infectious diseases. Proceedings of the National Academy of Sciences, 112(41), 12746-12751. https://doi.org/10.1073/pnas.1507442112 
Naimi, B., \& Araújo, M. B. (2016). sdm: a reproducible and extensible R platform for species distribution modelling. Ecography, 39(4), 368-375. https://doi.org/10.1111/ecog.01881

Nunney, L., Ortiz, B., Russell, S. A., Sánchez, R. R., \& Stouthamer, R. (2014). The complex biogeography of the plant pathogen Xylella fastidiosa: Genetic evidence of introductions and subspecific introgression in central America. PLOS ONE. https://doi.org/10.1371/journal.pone.0112463

Oreskes, N., Shrader-Frechette, K., \& Belitz, K. (1994). Verification, Validation, and Confirmation of Numerical Models in the Earth Sciences. Science, 263(5147), 641-646. https://doi.org/10.1126/science.263.5147.641

Packer, J. G., Meyerson, L. A., Richardson, D. M., Brundu, G., Allen, W. J., Bhattarai, G. P., \& Pyšek, P. (2017). Global networks for invasion science: benefits, challenges and guidelines. Biological Invasions, 19(4), 1081-1096. https://doi.org/10.1007/s10530-016-1302-3

Parker, J. D., Torchin, M. E., Hufbauer, R. A., Bossdorf, O., Byers, J. E., Dunn, A. M., \& Wolfe, L. (2013). Do invasive species perform better in their new range. Ecology, 94(5), 1-8. https://doi.org/10.1890/12-1810.1

Peterson, A. T., Soberón, J., Pearson, R. G., Anderson, R. P., Martínez-Meyer, E., Nakamura, M., \& Bastos Araujo, M. (2011). Ecological niches and geographic distributions (Vol. 49). Princeton, Ny: Princeton University Press.

Phillips, S. J., Anderson, R. P., Dudík, M., Schapire, R. E., \& Blair, M. E. (2016). Opening the black box: an open-source release of Maxent. Ecography. https://doi.org/10.1111/ecog.02537

Phillips, S. J., \& Dudi, M. (2008). Modeling of species distributions with Maxent: new extensions and a comprehensive evaluation. Ecography, 31, 161-175.

Pimentel, D., Zuniga, R., \& Morrison, D. (2005). Update on the environmental and economic costs associated with alien-invasive species in the United States. Ecological Economics. https://doi.org/10.1016/j.ecolecon.2004.10.002

Purcell, A. H. (1997). Xylella fastidiosa, a regional problem or global threat? Journal of Plant Pathology, 79(2), 99-105.

R Core Team. (2017). R: A Language and Environment for Statistical Computing. R Foundation for Statistical Computing. Vienna: R. Foundation for Statistical Computing. https://doi.org/10. 1007/978-3-540-74686-7

Ramírez-Albores, J. E., Bustamante, R. O., \& Badano, E. I. (2016). Improved predictions of the geographic distribution of invasive plants using climatic niche models. PLoS ONE, 11(5), 1-14. https://doi.org/10.1371/journal.pone.0156029 
Rapicavoli, J., Ingel, B., Blanco-Ulate, B., Cantu, D., \& Roper, C. (2018). Xylella fastidiosa: an examination of a re-emerging plant pathogen. Molecular Plant Pathology, 19(4), 786-800. htps://doi.org/10.1111/mpp. 12585

Redak, R. A., Purcell, A. H., Lopes, J. R. S., Blua, M. J., Mizell III, R. F., \& Andersen, P. C. (2004). The biology of xylem fluid-feeding insect vectors of Xylella fastidiosa and their relation to disease epidemiology. Annual Review of Entomology, 49(1), 243-270. https://doi.org/10.1146/annurev.ento.49.061802.123403

Ricciardi, A., Blackburn, T. M., Carlton, J. T., Dick, J. T. A., Hulme, P. E., lacarella, J. C., \& Aldridge, D. C. (2017). Invasion Science: A Horizon Scan of Emerging Challenges and Opportunities. Trends in Ecology and Evolution, 32(6), 464-474. https://doi.org/10.1016/j.tree.2017.03.007

Robinson, G. M. (2018). New frontiers in agricultural geography: Transformations, food security, land grabs and climate change. Boletin de la Asociación de Geógrafos Españoles, 2018(78), 148. https://doi.org/10.21138/bage.2710

Rodríguez-Labajos, B., Binimelis, R., \& Monterroso, I. (2009). Multi-level driving forces of biological invasions. Ecological Economics, 69(1), 63-75. https://doi.org/10.1016/j.ecolecon.2009.08.022

Saponari, M., Giampetruzzi, A., Loconsole, G., Boscia, D., \& Saldarelli, P. (2018). Xylella fastidiosa in olive in Apulia: where we stand. Phytopathology, 1-12. https://doi.org/10.1094/PHYTO-08-18-0319-FI

Seebens, H., Blackburn, T. M., Dyer, E. E., Genovesi, P., Hulme, P. E., Jeschke, J. M., \& Essl, F. (2017). No saturation in the accumulation of alien species worldwide. Nature Communications, 8 , 14435. https://doi.org/10.1038/ncomms 14435

Seebens, H., Essl, F., Dawson, W., Fuentes, N., Moser, D., Pergl, J., \& Blasius, B. (2015). Global trade will accelerate plant invasions in emerging economies under climate change. Global Change Biology, 21(11), 4128-4140. https://doi.org/10.1111/gcb.13021

Sicard, A., Zeilinger, A. R., Vanhove, M., Schartel, T. E., Beal, D. J., Daugherty, M. P., \& Almeida, R. P. P. (2018). Annual Review of Phytopathology Xylella fastidiosa: Insights into an Emerging Plant Pathogen. Annual Review of Phytopathology, 56, 9.1-9.22. https://doi.org/10.1146/annurev-phyto-080417

Steffen, W., Rockström, J., Richardson, K., Lenton, T. M., Folke, C., Liverman, D., \& Schellnhuber, H. J. (2018). Trajectories of the Earth System in the Anthropocene. Proceedings of the National Academy of Sciences, 115(33), 8252-8259. https://doi.org/10.1073/pnas.1810141115 
Strona, G., Carstens, C. J., \& Beck, P. S. A. (2017). Network analysis reveals why Xylella fastidiosa will persist in Europe. Scientific Reports, 7(1). https://doi.org/10.1038/s41598-017-00077-z

Tingley, R., García-Díaz, P., Arantes, C. R. R., \& Cassey, P. (2018). Integrating transport pressure data and species distribution models to estimate invasion risk for alien stowaways. Ecography. hitps://doi.org/10.1111/ecog.02841

Václavík, T., \& Meentemeyer, R. K. (2009). Invasive species distribution modeling (iSDM): Are absence data and dispersal constraints needed to predict actual distributions? Ecological Modelling, 220(23), 3248-3258. https://doi.org/10.1016/j.ecolmodel.2009.08.013

Václavík, T., \& Meentemeyer, R. K. (2012). Equilibrium or not? Modelling potential distribution of invasive species in different stages of invasion. Diversity and Distributions, 18(1), 73-83. https://doi.org/10.1111/j.1472-4642.2011.00854.x

Waters, C. N., Zalasiewicz, J., Summerhayes, C., Barnosky, A. D., Poirier, C., Ga uszka, A., \& Wolfe, A. P. (2016). The Anthropocene is functionally and stratigraphically distinct from the Holocene. Science, 351(6269), 137-148. https://doi.org/10.1126/science.aad2622

Wells, J. M., Raju, B. C., Hung, H.-Y., Weisburg, W. G., Mandelco-Paul, L., \& Brenner, D. J. (1987). Xylella fastidiosa gen. nov.: gram-negative, xylem-limited, fastidious plant bacteria related to $<i>$ Xanthomonas<i/> spp. International Journal of Systematic Bacteriology, 37(2), 136-143. https://doi.org/10.1099/00207713-37-2-136

Zhu, G. P., \& Peterson, A. T. (2017). Do consensus models outperform individual models? Transferability evaluations of diverse modeling approaches for an invasive moth. Biological Invasions, 19(9), 2519-2532. https://doi.org/10.1007/s10530-017-1460-y 